\title{
Atomistic Study of fundamental character and motion of dislocations in Intermetallic $\mathrm{Al}_{2} \mathbf{C u}$
}

\author{
Qing Zhou ${ }^{1,2}$, Jian Wang ${ }^{2, * *}$, Amit Misra $^{3}$, Ping Huang ${ }^{1}{ }^{*}$ Fei Wang ${ }^{4, *}$, Kewei Xu ${ }^{1}$ \\ ${ }^{1}$ State key Laboratory for Mechanical Behavior of Material, School of Materials Science and Engineering, \\ Xi'an Jiaotong University, Xi'an, 710049, People's Republic of China \\ ${ }^{2}$ Mechanical and Materials Engineering, University of Nebraska-Lincoln, Lincoln, NE 68588 USA \\ ${ }^{3}$ Department of Materials Science and Engineering, University of Michigan, Ann Arbor, Michigan 48109, \\ USA \\ ${ }^{4}$ State Key Laboratory for Strength and Vibration of Mechanical Structures, School of Aerospace, Xi'an \\ Jiaotong University, Xi'an 710049, People's Republic of China
}

\begin{abstract}
Atomic scale study of the character and motion of dislocations in $\mathrm{Al}_{2} \mathrm{Cu}$ will provide insights into understanding the superior mechanical properties of $\mathrm{Al}-\mathrm{Al}_{2} \mathrm{Cu}$ alloys. Using atomistic simulations, we studied seven potential slip systems $(110)<001>,(010)<001>$, $\left.(310)<001\rangle,(010)<100\rangle,(110)<1 \overline{1} 0\rangle,(110) \frac{1}{2}<1 \overline{1} 1\right\rangle$ and $\left.(112) \frac{1}{2}<\overline{1} 11\right\rangle$ in $\mathrm{Al}_{2} \mathrm{Cu}$ with body centered tetragonal structure. We found that three edge dislocations with Burgers vector <001> on glide planes (110), (010), and (310), show an extended core and are predicted to be glissile at room and moderate temperatures. Other four edge dislocations associated with slip systems $\left.(010)\langle 100\rangle,(110)\langle 1 \overline{1} 0\rangle,(110) \frac{1}{2}<1 \overline{1} 1\right\rangle$ and $(112) \frac{1}{2}\langle\overline{1} \overline{1} 1\rangle$ and three screw dislocations with Burgers vectors $\langle 001\rangle,\langle 110\rangle$, and $\frac{1}{2}\langle\overline{1} \overline{1} 1\rangle$ show a condensed core, and exhibit significantly higher Peierls barrier for glide at room temperature. Furthermore, the interaction of dislocation dipole associated with slip system $(110)<001>$ results in the climb of the extended-core dislocation at room temperature through three stages: the extended core condenses, the leading partial dislocation climbs accompanying the creation of vacancies (resulting in a non-planar core), and the two partials with non-planar core collectively glide on the neighboring slip planes associated with atomic shuffles.
\end{abstract}

Keywords: Intermetallic, Dislocation, Climb, Atomistic modeling

\footnotetext{
* Correspondent authors: wangfei@ mail.xjtu.edu.cn (Fei Wang); huangping@ mail.xjtu.edu.cn (Ping Huang); jianwang@unl.edu (Jian Wang).
} 


\section{Introduction}

Metal-intermetallic eutectic composites are potential candidates for structural applications at ambient and elevated temperatures (Umakshi, 1993). Al-based alloys, such as Al-Cu (Park et al., 2009, 2010; Yanilkin et al., 2014; Csontos et al., 2005; Csontos and Starke, 2005; Prados et al., 2013; Bonnet and Loubradou, 2002b; Liu, 2011), Al-Mg (Youssef et al., 2006; Jobba et al., 2015; Zhou et al., 2003; Hales and McNelley, 1988), Al-Ni (Muñoz-Morris et al., 2009; Rajan et al., 2008; Shield, 1995), Al-Si (Mabuchi and Higashi, 2001; Nogita et al., 2006; Picu et al., 2011), etc. have attracted the most attention because of their lightweight, four times lower density as compared to steel (Umakshi, 1993). Most of the reported Al-based state-of-the-art commercial alloys are precipitation or dispersion hardened. For $\mathrm{Al}-\mathrm{Cu}$ alloys, $\mathrm{Al}_{2} \mathrm{Cu}$ precipitates are formed in plate-like structures (Park et al., 2009, 2010; Yanilkin et al., 2014; Csontos et al., 2005; Csontos and Starke, 2005; Prados et al., 2013; Bonnet and Loubradou, 2002b; Liu, 2011; Russell and Ashby, 1970). These precipitates developed several well-defined orientation relationships (ORs) with matrix Al (Gao et al., 2014; Howe et al., 1995; Ignat et al., 1978; Knowles and Stobbs, 1988). Under mechanical loading at room temperature, $\mathrm{Al}_{2} \mathrm{Cu}$ precipitates in these composites elastically deform due to the brittle nature of $\mathrm{Al}_{2} \mathrm{Cu}$ phases (high friction force associated with dislocations motion), acting as strong obstacles for dislocation motion (Prados et al., 2013; Han et al., 2004; Bonnet, 2002a). When precipitates and matrix geometrically co-deform under mechanical loading, $\mathrm{Al}_{2} \mathrm{Cu}$ precipitates may be subjected to higher stresses than matrix Al due to its higher elastic modulus than Al. They elastically deform without apparent plasticity at room temperature, and often failure due to cracks (Chadwick, 1963; Chanda and Murty, 1992; Khan and Liu, 2012). At elevated temperatures $\left(>300^{\circ} \mathrm{C}\right), \mathrm{Al}_{2} \mathrm{Cu}$ precipitates can plastically deform via dislocations (Chadwick, 1963; Chanda and Murty, 1992; Khan and Liu, 2012). Dislocations in intermetallic phases are preferably nucleated from phase boundaries because of interface ledges/steps and slip transmission for dislocations from matrix into $\mathrm{Al}_{2} \mathrm{Cu}$ precipitates (Bonnet, 2002a; Li and Wawner, 1998; Nie and Muddle, 2000).

In order to enhance ductility and strength at room temperature, the current focus is on producing $\mathrm{Al}-\mathrm{Cu}$ alloys with a high volume fraction of intermetallic reinforcement (in 
other words, reduction in interphase spacing or interlamellar spacing for regular eutectic) with the help of either rapid solidification with alloying additions (Park et al., 2009, 2010; Shield, 1995; Witkin et al., 2003; Otsuka and Shimizu, 1970; Trivedi et al., 2004) or severe plastic deformation (SPD) techniques (Prados et al., 2013; Murayama et al., 2001; Loucif et al., 2010; Tao et al., 2013; Pérez-Prado and Ruano, 2004; Valiev et al., 2000). For example, Al-Cu-Si alloys containing a bimodal distribution of eutectic colonies exhibit a high strength and a compressive plastic strain of $2 \%$ at room temperature (Park et al., 2009, 2010). Severe plastic deformation techniques, such as equal channel angular pressing (Prados et al., 2013; Murayama et al., 2001), high pressure torsion (Loucif et al., 2010; Tao et al., 2013), and accumulated rolling (PérezPrado and Ruano, 2004; Valiev et al., 2000), have been demonstrated to produce the bulk nanostructured metals with a grain size or layer thickness in nanometer or submicrometer ranges (Pérez-Prado and Ruano, 2004; Valiev et al., 2000; Zeng et al., 2013; Uenishi et al., 1991), accompanied with a high density of dislocations stored in intermetallic phase. In situ straining experiments of $\mathrm{Al}_{2} \mathrm{Cu}-\mathrm{Al}$ composites in a transmission electron microscope (TEM) have shown dislocations bypassing through $\mathrm{Al}_{2} \mathrm{Cu}$ plate-shaped particles by shear at multiple locations along the interphase boundaries, and the formation of a complex configuration of lattice dislocations pinned at both ends on a particle interface (Liu, 2011; Russell and Ashby, 1970). In addition, SPD also leads to the formation of non-equilibrium solid solutions (Uenishi et al., 1991; Yang et al., 2013), disordering (Korznikov et al., 1999) or amorphization (Inoue, 1998; Eckert et al., 1991) in intermetallic phase. The decomposition or instability of intermetallic phase during heavy plastic deformation has been partially ascribed to dislocations and defected interfaces created during straining (Umakshi, 1993). Dislocations have been demonstrated to provide rapid diffusion channels and adiabatic heating of the samples during plastic deformation (Hirth and Lothe, 1982; Schroll et al., 1998). Dislocations crossing the precipitates may drag the interstitial or vacancy atoms with them out of the precipitate (Gridnev and Gavrilyuk, 1982). In addition, it has been observed in experiments that dislocation climb occurs in intermetallic phase associated with the change in dislocation core structures (Umakshi, 1993; Appel, 2001; Anton et al., 1989). Moreover, creation of slip steps at the interphase boundaries of the precipitate may lead 
to their thermodynamic instability. Nevertheless, dislocations and their motion and reactions are presumed to be responsible for the structural instability of intermetallic phase.

The possible dislocation types in $\mathrm{Al}_{2} \mathrm{Cu}(\theta)$ are directly related to its $\mathrm{C} 16$ body centered tetragonal structure. An unit cell contains 12 atoms with internal coordinates of $\mathrm{Cu}:\{0,0,1 / 4\} ;\{0,0,3 / 4\} ;\{1 / 2,1 / 2,1 / 4\} ;\{1 / 2,1 / 2,3 / 4\} ;$ and $\mathrm{Al}:\{0.1541,0.6541,0\}$; $\{0.3459,0.1541,0\} ;\{0.8459,0.3459,0\} ;\{0.6541,0.8459,0\} ;\{0.8459,0.6541,0.5\}$; $\{0.6541,0.1541,0.5\} ;\{0.1541,0.3459,0.5\} ;\{0.3459,0.8459,0.5\}$. The most complete families of glide planes deduced from the close packed planes according to the crystallography of C16 body centered tetragonal structure are $\{110\},\{100\},\{011\}$, and $\{112\}$; the major slip systems include $\{110\}<001\rangle,\{110\} 1 / 2<111\rangle,\{200\}<001\rangle$, and $\{112\} 1 / 2<111>$ (Ignat and Durand, 1976). Dislocations with Burgers vector [110] have been identified along grain boundaries using high resolution TEM (Bonnet and Loubradou, 2002a,b). But it was not clear whether such dislocations could glide in $\mathrm{Al}_{2} \mathrm{Cu}$ $(\theta)$ because the Burgers vector is too large (Bonnet and Loubradou, 2002a; Chanda and Murty, 1992). In addition, a quite unusual core splitting has been observed for $(110) 1 / 2<111>$ on the (110) plane, and large planar faults have been noticed on (001) (Bonnet and Loubradou, 2002b; Knowles and Stobbs, 1988). In summary, $\mathrm{Al}_{2} \mathrm{Cu}(\theta)$ is brittle at lower temperatures, but plastically deformable via dislocation glide and climb at high temperatures. The brittle-ductile (BD) transition for $\mathrm{Al}_{2} \mathrm{Cu}(\theta)$ phase in $\mathrm{Al}^{-\mathrm{Al}_{2} \mathrm{Cu}}$ ( $\theta$ ) composites occurs at $300^{\circ} \mathrm{C}$ (Ignat et al., 1978), and at $375^{\circ} \mathrm{C}$ in $\mathrm{Al}_{2} \mathrm{Cu}(\theta)$ single crystals and polycrystals by compression testing (Chanda and Murty, 1992), indicating the drop of the $\mathrm{BD}$ transition temperature of $\mathrm{Al}_{2} \mathrm{Cu}(\theta)$ in composites. With decreasing the interphase spacing and the thickness of intermetallic phase in metallic-intermetallic composites, the interaction force among dislocations accumulated on the adjacent phase boundaries will increases and may favor slip transmission and dislocation glide in intermetallic phase (Salehinia et al., 2014; Wang and Misra, 2014b; Embury and Hirth, 1994). As demonstrated in Al-TiN system, room temperature plasticity is achievable (Li et al., 2014). However, plasticity in $\mathrm{Al}_{2} \mathrm{Cu}$ lamellae at room temperature, more precisely, characteristics of dislocations, has been rarely studied at atomic scale (Chen and Ma, 2013). 
In this paper, we employed molecular dynamics/statics (MD/MS) simulations with empirical interatomic potentials (Apostol and Mishin, 2011) to study characteristics of dislocations associated with slip systems $(110)<001>$, $(010)<001>,(310)<001>$, $\left.(010)<100\rangle,(110)\langle 1-10\rangle,(110) \frac{1}{2}<1 \overline{1} 1\right\rangle$ and $\left.(112) \frac{1}{2}<\overline{1} \overline{1} 1\right\rangle$. Furthermore, we investigated interaction of dislocation dipoles that mimic general cases of dislocations in a confined volume (precipitate), where dislocations nucleated from the adjacent interfaces and glide towards each other. Most intriguingly, we found that the extended-core dislocation can climb at moderate temperatures. Correspondingly, this paper was organized as follows: core structure and motion of dislocations in $\mathrm{Al}_{2} \mathrm{Cu}$ (Section 2); interaction of dislocation dipoles (Section 3); summary and conclusions (Section 4).

\section{Slip systems in $\mathrm{Al}_{2} \mathrm{Cu}$}

\subsection{Molecular dynamics simulations}

The possible dislocation types in $\mathrm{Al}_{2} \mathrm{Cu}(\theta)$ are directly related to its $\mathrm{C} 16$ structure (a body centered tetragonal structure) with the lattice $a=b=0.606 \mathrm{~nm}$ and $\mathrm{c}=0.487 \mathrm{~nm}$. The crystal $\mathrm{Al}_{2} \mathrm{Cu}(\theta)$ at room temperature has the anisotropic elastic constants $\mathrm{C}_{11}=159 \mathrm{GPa}, \mathrm{C}_{12}=63 \mathrm{GPa}, \mathrm{C}_{13}=49 \mathrm{GPa}, \mathrm{C}_{33}=163 \mathrm{GPa}, \mathrm{C}_{44}=29 \mathrm{GPa}, \mathrm{C}_{66}$ = $46 \mathrm{GPa}$ (Fribourg-Blanc et al., 1979). The most complete families of glide planes in $\mathrm{Al}_{2} \mathrm{Cu}(\theta)$ are $\{110\},\{100\},\{310\}$ and $\{112\}$. The corresponding slip systems are $(110)\langle 001\rangle,(010)<001\rangle,(310)<001\rangle,(010)<100\rangle,(110)<1-10\rangle,(110) \frac{1}{2}\langle 1 \overline{1} 1\rangle$ and $\left.(112) \frac{1}{2}<\overline{1} \overline{1} 1\right\rangle$. Using atomistic simulations with empirical potentials, we studied core structure of dislocations associated with these slip systems. The potentials have been tested to well reproduce lattice constants, cohesive energy, elastic properties, compared to Density Functional Theory calculations and experiments (Apostol and Mishin, 2011; Fribourg-Blanc et al., 1979). In what follows, we describe the simulation details and summarize the results.

A rectangular single crystal model (Figure 1) with a periodic boundary condition along z-axis is adopted. The model is divided into a two-part computational cell (Wang et al., 2008, 2011a). One part, region 1, contains moveable atoms embedded in a semi-rigid part, region 2. The dimensions of the simulation cell are around $60 \mathrm{~nm}$ in both the $\mathrm{x}$ 
direction and the $\mathrm{y}$ direction. The dimension along the $\mathrm{z}$-axis is greater than $1.7 \mathrm{~nm}$, varying with the line direction of the studied dislocation. Lattice glide dislocations are introduced in the model by the application of the anisotropic Barnett-Lothe solutions for the displacement field of a dislocation (Barnett and Lothe, 1974). This field is applied to both the moveable and the semi-rigid regions of the model. The introduced dislocation line is parallel to the z-axis. Molecular dynamics simulations are carried out for $100 \mathrm{ps}$ at a constant temperature of $300 \mathrm{~K}$, and then followed by quenching molecular dynamics until the maximum force acting on atoms in region 1 does not exceed $5 \mathrm{pN}$.

Line energy of a dislocation is calculated by integrating the excess energy of atoms inside cylinders as a function of the radius $r$ (Hirth and Lothe, 1982; Wang et al., 2013), as shown in Figure 1. Core structure of a dislocation is characterized by using disregistry analysis (Wang et al., 2012; 2014a). In this analysis, pairs of atoms that straddle the desired shear plane are first identified in a reference, relaxed system. The vector $\vec{r}_{i j}^{r}$ describes the relative position, $\vec{r}_{i j}^{r}=\vec{r}_{i}^{r}-\vec{r}_{j}^{r}$, between the $i$ th atom and the $j$ th atom that forms a pair in the reference, relaxed system, where the vector $\vec{r}_{i}^{r}$ describes the position of the $i$ th atom in the reference system. The displacements of these atoms in the

sheared system are determined with respect to the reference system. The vector $\vec{r}_{i j}^{d}$ describes the relative position, $\vec{r}_{i j}^{d}=\vec{r}_{i}^{d}-\vec{r}_{j}^{d}$, between the $i$ th atom and the $j$ th atom in the sheared system, where the vector $\vec{r}_{i}^{d}$ describes the position of the $i$ th atom in the sheared system. Disregistry vector is calculated as the difference of the two vectors, $\vec{r}_{i j}^{d}-\vec{r}_{i j}^{r}$.

\subsection{Slips on the plane (110)}

Figures 2 (a) and (b) show the atomic structures of projection of a unit cell along the $\langle 1 \overline{1} 0\rangle$ direction and the $\langle 110\rangle$ direction, respectively. The crystallography of the projected atomic structure in Figure 2(a) shows the atomic stacking of eight (110) planes in a unit cell: $\ldots \mathrm{CuAl}_{\mathrm{A}} \mathrm{Al}_{\mathrm{B}} \mathrm{Al}_{\mathrm{A}} \mathrm{CuAl}_{\mathrm{C}} \mathrm{Al}_{\mathrm{D}} \mathrm{Al}_{\mathrm{C}} \ldots$, implying two possible slip planes between $\mathrm{Al}_{\mathrm{C}}-\mathrm{Al}_{\mathrm{D}}$ (as same as $\mathrm{Al}_{\mathrm{A}}-\mathrm{Al}_{\mathrm{B}}$ ) or between $\mathrm{Al}_{\mathrm{C}}-\mathrm{Cu}$ (as same as $\mathrm{Al}_{\mathrm{A}}-\mathrm{Cu}$ ). The interplanar spacing is $0.14 \mathrm{~nm}$ between $\mathrm{Al}_{C}-\mathrm{Al}_{\mathrm{D}}$, and $0.07 \mathrm{~nm}$ between $\mathrm{Al}_{\mathrm{C}}-\mathrm{Cu}$. Figure 2(b) is the plan-view of eight (110) planes, indicating that the areal density of the eight atomic planes in an unit cell: $4 \mathrm{Cu}$ atoms in one $\mathrm{Cu}$ plane, $4 \mathrm{Al}$ atoms in one $\mathrm{Al}_{\mathrm{B}}$ or $\mathrm{Al}_{\mathrm{D}}$ 
plane, and $2 \mathrm{Al}$ atoms in one $\mathrm{Al}_{\mathrm{A}}$ or $\mathrm{Al}_{\mathrm{C}}$ plane. It is also noticed that the translation between $\mathrm{Al}_{\mathrm{A}}$ and $\mathrm{Al}_{\mathrm{C}}$ or between $\mathrm{Al}_{\mathrm{B}}$ and $\mathrm{Al}_{\mathrm{D}}$ can be achieved through in-plane shear of $1 / 2<001>$. The higher atomic areal density (of planes $\mathrm{Cu}, \mathrm{Al}_{\mathrm{D}}$ and $\mathrm{Al}_{\mathrm{B}}$ ) suggests possible slip planes between $\mathrm{Cu}-\mathrm{Al} l_{\mathrm{A}}, \mathrm{Cu}-\mathrm{Al}_{\mathrm{C}}, \mathrm{Al}_{\mathrm{C}}-\mathrm{Al}_{\mathrm{D}}$, and $\mathrm{Al}_{\mathrm{B}}-\mathrm{Al}_{\mathrm{A}}$. Moreover, the larger interplanar spacing $(0.14 \mathrm{~nm})$ implies the geometrically favored slip plane between $\mathrm{Al}_{\mathrm{C}^{-}}$ $\mathrm{Al}_{\mathrm{D}}$ or $\mathrm{Al}_{\mathrm{B}}-\mathrm{Al}_{\mathrm{A}}$.

We further examined generalized stacking fault energy on the possible slip planes using molecular statics method where atoms are allowed to relax normal to the shear plane (Salehinia et al., 2015; Shao et al., 2015). Figures 3(a) and 3(b) show the energy surfaces of the $\mathrm{Cu}-\mathrm{Al}_{\mathrm{A}}$ and $\mathrm{Al}_{\mathrm{B}}-\mathrm{Al}_{\mathrm{A}}$ shear planes and three possible shears associated with three lattice dislocations: $\left.\mathbf{b}_{1}=\langle 001\rangle, \mathbf{b}_{2}=\frac{1}{2}<\overline{1} \overline{1} 1\right\rangle$, and $\mathbf{b}_{3}=\langle 1 \overline{1} 0\rangle$. Taking the shear along $<001>$ as an example, it is noticed that stable stacking faulted structures formed in association with the shear $\frac{1}{2}<001>$ on the slip planes $\mathrm{Cu}-\mathrm{Al}_{\mathrm{A}}$ and $\mathrm{Al}_{\mathrm{B}}-\mathrm{Al}_{\mathrm{A}}$. But the stacking faulted structure in the shear plane $\mathrm{Al}_{\mathrm{B}}-\mathrm{Al}_{\mathrm{A}}$ has the lower fault energy (Figure 3(c)). Thus a full dislocation with Burgers vector <001> might be extended into two

partials with Burgers vector $\frac{1}{2}<001>$ and bounded by a stacking fault. The lower stacking fault energy further suggests the preferred slip plane between $\mathrm{Al}_{\mathrm{B}}-\mathrm{Al}_{\mathrm{A}}$ because a wider core is generally associated with a low friction force for the glide of the dislocation on this plane (Hirth and Lothe, 1982).

\section{a) Slip system (110)<001>}

A dislocation with Burges vector $<001>$ is introduced on the $\mathrm{Cu}-\mathrm{Al}_{\mathrm{A}}$ and $\mathrm{Al}_{\mathrm{B}}-\mathrm{Al}_{\mathrm{A}}$ shear planes for comparison. The relaxed dislocation structures are shown in Figures $4 \mathrm{a}$ and $4 \mathrm{~b}$. Disregistry analysis across the sheared plane revealed an extended core for the dislocation on the $\mathrm{Al}_{\mathrm{B}}-\mathrm{Al}_{\mathrm{A}}$ shear plane with a separation of $1.25 \mathrm{~nm}$ where two partials have Burgers vector of $1 / 2[001]$, and a condensed core for the dislocation on the $\mathrm{Cu}-\mathrm{Al}_{\mathrm{A}}$ shear plane. This is consistent with the stacking fault energies. The elastic energy of the dislocation line is computed by integrating the excess energy of atoms around the center of the dislocation core, showing that the line energy for the dislocation on two different shear planes is linearly dependent on the logarithm of the radius, and the dislocation with an extended core structure on the $\mathrm{Al}_{\mathrm{B}}-\mathrm{Al}_{\mathrm{A}}$ shear plane has the lower core energy $(\Delta E$ is 
the difference in the dislocation line energy when the dislocation resides between $\mathrm{Cu}-\mathrm{Al}_{\mathrm{A}}$ and $\mathrm{Al}_{\mathrm{B}}-\mathrm{Al}_{\mathrm{A}}$ ), as shown in Figure $4 \mathrm{~d}$.

We further calculated the energy profile with respect to dislocation motion along the shear direction $<001>$ on the $\mathrm{Al}_{\mathrm{B}}-\mathrm{Al}_{\mathrm{A}}$ shear plane. Using Nudge Elastic Band method with 15 intermediate images (Henkelman and Jónsson, 2000), we computed energy change as a function of the shear for a full dislocation ([001]) and a partial dislocation $(1 / 2[001])$. The initial 15 intermediate states are linearly interpolated between the initial and final states, and then relaxed using NEB method to minimize the energy and force. The initial position and the final position of the dislocation can be well identified from the disregistry plot with a separation of one periodic length. However, the position of the dislocation in an intermediate state is difficult to determine. We determined the position of the dislocation using the concept of a virtual dislocation [Wang et al., 2012; Shao et al., 2015]. We integrated the shear area under the disregistry plot, and then converted the variation of shear areas to the dislocation position. For example, for the $i^{\text {th }}$ state, we calculated the change in the shear area on the glide plane with respect to the initial state by integrating the relative displacement $D_{i}$ along the glide plane. The position of the virtual dislocation of the $\mathrm{i}^{\text {th }}$ state is calculated to be $\mathrm{D}_{\mathrm{i}} / \mathrm{D}_{17}$, ranging from 0 to 1 , where 0 corresponds to the initial and 1 corresponds to the final position. Figure $4 \mathrm{e}$ shows the energy change $E$ as a function of dislocation glide distance $x$; and Figure $4 \mathrm{f}$ shows the generalized shear stress that is calculated as $-\frac{d E}{d x}$. The Peierls stress is then estimated to be $2 \mathrm{GPa}$ for a partial dislocation and $2.5 \mathrm{GPa}$ for a full dislocation (Wang et al., 2011b). We found that the glide of a partial experiences a lower energy barrier than a full dislocation, indicating the glide of the full dislocation is accomplished through a startstop-start mechanism (Liu et al., 2011; Wang et al., 2010), i.e., the leading partial moves under shear stress, causing the extension of stacking fault and corresponding stress drop around the leading partial, then the leading partial stops for a while. Meanwhile, the trialing partial moves towards the leading partial under shear stress and the generalized stress associated with reducing the stacking fault, and then stops. By repeating this process, a full dislocation moves under shear stress. We studied the glide of a dislocation by performing molecular dynamic simulations at different constant shear stresses. The dynamic straining condition was employed to retain a constant shear stress. If the 
dislocation did not obviously move (the glide distance is greater than two times the magnitude of the Burgers vector) in the first 200 picoseconds during MD simulations, then we will increase the applied shear stress. At the temperature $200 \mathrm{~K}$ and under a constant shear stress of $2.0 \mathrm{GPa}$, the dislocation obviously glides for $13 \mathrm{~nm}$.

\section{b) Slip systems (110) $\frac{1}{2}<1 \overline{1} 1>$ and $(110)<1 \overline{10}>$}

The edge dislocation with Burgers vector $\frac{1}{2}<1 \overline{1} 1>$ on the plane (110) has a condensed core (Figure 5a), and experiences high energy barrier as moving along the shear direction $\langle 1 \overline{1} 1\rangle$. When the temperature was increased up to $600 \mathrm{~K}$, we observed its glide under a shear stress of $4.5 \mathrm{GPa}$. Below the temperature, the dislocation does not glide even as the shear stress is increased up to $6 \mathrm{GPa}$. The dislocation with Burgers vector $\langle 1 \overline{1} 0\rangle$ shows a more complicated core structure (Figure $5 \mathrm{~b}$ ) and correspondingly it does not glide even when the temperature is increased to $800 \mathrm{~K}$ and shear stress to 10 GPa. This is possibly attributed to the complicated core corresponding to the large Burgers vector.

\subsection{Slip on (010) plane}

Figures 6 (a) and (b) show the atomic structures of projection of a unit cell along the $\langle 100\rangle$ direction and the $\langle 010\rangle$ direction, respectively. The crystallography of the projected atomic structure in Figure 6(a) shows the atomic stacking of six (010) planes in a unit cell: ... $\mathrm{Cu}_{\mathrm{B}} \mathrm{Al}_{\mathrm{A}} \mathrm{Al}_{\mathrm{B}} \mathrm{Cu}_{\mathrm{A}} \mathrm{Al}_{\mathrm{C}} \mathrm{Al}_{\mathrm{D}} \mathrm{Cu}_{\mathrm{B}} \ldots$, implying two possible slip planes between $\mathrm{Al}_{\mathrm{A}}-\mathrm{Al}_{\mathrm{B}}$ (as same as $\mathrm{Al}_{\mathrm{C}}-\mathrm{Al}_{\mathrm{D}}$ ) or between $\mathrm{Cu}_{\mathrm{B}}-\mathrm{Al}_{\mathrm{A}}$ (as same as $\mathrm{Al}_{\mathrm{B}}-\mathrm{Cu}_{\mathrm{A}}$ ). The interplanar spacing is $0.123 \mathrm{~nm}$ between $\mathrm{Cu}_{\mathrm{B}}-\mathrm{Al}_{\mathrm{A}}$, and $0.115 \mathrm{~nm}$ between $\mathrm{Al}_{\mathrm{A}}-\mathrm{Al}_{\mathrm{B}}$. Figure 6(b) is the plan-view of six (010) planes, indicating that the areal density of atomic planes in an unit cell: $2 \mathrm{Cu}$ atoms in one $\mathrm{Cu}_{\mathrm{A}}$ or $\mathrm{Cu}_{\mathrm{B}}$ plane, $2 \mathrm{Al}$ atoms in one $\mathrm{Al}_{\mathrm{A}}$ or $\mathrm{Al}_{\mathrm{B}}$ or $\mathrm{Al}_{\mathrm{C}}$ or $\mathrm{Al}_{\mathrm{D}}$ plane. From crystallographic view, the translation between the neighboring $\mathrm{Al}_{\mathrm{A}}$ and $\mathrm{Al}_{\mathrm{B}}$ or $\mathrm{Al}_{\mathrm{C}}$ and $\mathrm{Al}_{\mathrm{D}}$ planes can be achieved through the in-plane shear of $1 / 4<102>$ or $1 / 4<\overline{1} 02>$. This is not along the shear associated with the dislocation with Burgers vector $\langle 100\rangle$ or $<001>$. Thus, the possible slip planes are between $\mathrm{Cu}$ and $\mathrm{Al}$.

We examined generalized stacking fault energy on the possible slip plane of $\mathrm{Cu}_{\mathrm{B}}-$ $\mathrm{Al}_{\mathrm{A}}$. Figure 6(c) show the energy surfaces of the $\mathrm{Cu}_{\mathrm{B}}-\mathrm{Al}_{\mathrm{A}}$ shear plane and two possible shears associated with two lattice dislocations: $\mathbf{b}_{4}=\langle 001\rangle$ and $\mathbf{b}_{5}=\langle 100\rangle$. It also indicates 
the shear along $\left\langle 102>\right.$ or $\left\langle\overline{1} 02>\right.$ associated with the translation between $\mathrm{Al}_{\mathrm{A}}-\mathrm{Al}_{\mathrm{B}}$ or between $A l_{C}-A l_{D}$ is kinetically unfavorable because of a high energy barrier. Figure $6(d)$ shows generalized stacking fault energy profile along the two directions <100> and $<001>$. It is noticed that stable stacking fault structures could be formed associated with the shear $\frac{1}{2}<100>$ or $\frac{1}{2}<001>$ on the slip plane $\mathrm{Cu}_{\mathrm{B}}-\mathrm{Al}_{\mathrm{A}}$. Thus a full dislocation with Burgers vector $<100>$ or $<001>$ might be extended into two partials with Burgers vector $\frac{1}{2}<100>$ or $\frac{1}{2}<001>$ and bounded by a stacking fault.

\section{a) Slip systems $(010)<001>$}

Corresponding to the low stacking fault energy, a dislocation with Burgers vector $\boldsymbol{b}_{4}=[001]$ was introduced in a single crystal with different separation distance $d$ between two partials $\left(\frac{1}{2}<001>\right)$. We found that the dislocation with extended cores can be stabilized at room temperature (Figure $7 \mathrm{a}$ and $7 \mathrm{~b}$ ) although the line energy of these dislocations linearly increases with the separation distance (Figure 7d). This suggests a high friction force associated with the glide of partial dislocation. So, partial dislocations are not preferred in the slip systems $(010) \frac{1}{2}<001>$. This seems consistent with the high stacking fault energy $0.8 \mathrm{~J} / \mathrm{m}^{2}$ compared to the faulted plane in the slip system $(110)<001>$ $\left(0.65 \mathrm{~J} / \mathrm{m}^{2}\right)$. We further examined the glide of a dislocation $\boldsymbol{b}_{4}$ by using MD simulation, and observed the motion of a full dislocation under shear stress of $3.0 \mathrm{GPa}$ at temperature $400 \mathrm{~K}$. Even when the dislocation in MD model has an extended core, the glide of the dislocation is realized through condensing the core and then gliding. MD simulations demonstrated the gliding of the dislocation $\boldsymbol{b}_{4}$ for $2 \mathrm{~nm}$ in the first 200 picoseconds, indicating that the gliding of $\boldsymbol{b}_{4}$ is much slower than $\boldsymbol{b}_{1}$.

\section{b) Slip systems $(010)<100>$}

A dislocation with Burgers vector $\boldsymbol{b}_{5}=<100>$ on the glide plane (010) also shows a condensed core (Figure 7c). Compared to a dislocation associated with slip system $(010)<001>$, the stacking fault energy associated with the shear $\left.\frac{1}{2}<100\right\rangle$ is similar to that associated with the shear $\frac{1}{2}<001>$. However, extended core associated with the dislocation $(010)<100>$ is unstable. This could be ascribed to its greater shear magnitude $<001>$ than the shear $\langle 100\rangle$ of a dislocation $(010)<100\rangle$, in other words, the shear direction $\langle 100\rangle$ is not compact. We further performed MD simulations under shear stress above $8 \mathrm{GPa}$ and 
at high temperature $600 \mathrm{~K}$. We did not observe the motion of a full dislocation $(010)<001>$.

\subsection{Slip planes (310) and (112)}

The atomic structure of the projection of a unit cell along the $\langle 1 \overline{3} 0\rangle$ direction in Figures 8 (a) shows that atomic plane (310) contains both $\mathrm{Cu}$ and $\mathrm{Al}$ with average atomic areal density of 2.607 atom $/ \mathrm{nm}^{2}$. Moreover, it is not atomically flat with interplanar spacing of $0.269 \mathrm{~nm}$. The preferred shear on (310) plane is along <001〉, corresponding to the dislocation $\boldsymbol{b}_{6}=<001>$. The atomic structure of the projection of a unit cell along the $\langle 1 \overline{1} 0\rangle$ direction in Figures 8 (b) shows the stacking of atomic planes (112). Each stripe is composed of three atomic planes. The preferred shear happens between $\mathrm{Al}$ and $\mathrm{Al}$ atomic planes along the direction $\frac{1}{2}<\overline{1} \overline{1} 1>$.

An edge dislocation with Burgers vector $\boldsymbol{b}_{6}=<001>$ on the glide plane (310) has an extended core with a separation of $2.0 \mathrm{~nm}$ (Figure 8c). We performed MD simulations under shear stress $4.5 \mathrm{GPa}$ at high temperature of $600 \mathrm{~K}$, and observed the gliding of a full dislocation $(310)<001>$ for $1.2 \mathrm{~nm}$ in the first 200 picoseconds. However, the dislocation with Burgers vector $\mathbf{b}_{7}=\frac{1}{2}<\overline{1} \overline{1} 1>$ on the plane (112) shows a condensed core (Figure 8d), and do not glide even under a shear stress of $5 \mathrm{GPa}$ at $600 \mathrm{~K}$.

\subsection{Remarks}

So far we have examined core structures of seven edge dislocations. It is noticed that three edge dislocations $\left(\boldsymbol{b}_{1}, \boldsymbol{b}_{4}, \boldsymbol{b}_{6}\right)$ with Burgers vector $<001>$ on glide planes (110), (010), and (310), show extended cores. In particular, the dislocation $\boldsymbol{b}_{1}$ on (110) plane is dissociated into two partials with Burgers vector $1 / 2[001]$. Other four edge dislocations $\left(\boldsymbol{b}_{2}, \boldsymbol{b}_{3}, \boldsymbol{b}_{5}\right.$, and $\boldsymbol{b}_{7}$ ) show condensed core. This feature is consistent with the generalized stacking fault energies, as shown in Figure 9(a). Figures 9 (b-d) show atomic structures of screw dislocations with Burgers vectors $\langle 001\rangle,\langle 110\rangle$, and $1 / 2\langle 111\rangle$, revealing a condensed core for screw dislocations in $\mathrm{Al}_{2} \mathrm{Cu}$.

We observed the glide of the dislocation at certain conditions: $\boldsymbol{b}_{1}(110)<001>$ at $200 \mathrm{~K}$ and under shear stress of $2.0 \mathrm{GPa}, \boldsymbol{b}_{4}(010)<001>$ at $400 \mathrm{~K}$ under shear stress of 3 $\mathrm{GPa}$, and $\boldsymbol{b}_{6}(310)<001>$ at $600 \mathrm{~K}$ under shear stress of $4.5 \mathrm{GPa}$, and $\boldsymbol{b}_{2}(110) 1 / 2<1 \overline{1} 1>$ at 
$600 \mathrm{~K}$ under shear stress of $4.5 \mathrm{GPa}$. The easiest gliding dislocation is $\boldsymbol{b}_{1}$ which is also frequently observed in experiments (Howe et al., 1995; Gao et al., 2014; Ignat et al., 1978; Knowles and Stobbs, 1988). The other dislocations, $\boldsymbol{b}_{3}, \boldsymbol{b}_{5}, \boldsymbol{b}_{7}$, did not move at temperature above $600 \mathrm{~K}$ and under applied shear stress exceeding $6.0 \mathrm{GPa}$. This observation is consistent with the feature of dislocation cores: the glide of a dislocation experiences lower friction force when the dislocation has a wider, planar core (Hirth and Lothe, 1982). These results can account for room temperature brittleness and high temperature plasticity of $\mathrm{Al}_{2} \mathrm{Cu}(\theta)$ as more slip systems will be activated at high temperatures.

\section{Climb of the extended-core dislocation $b_{1}=[001]$ on (110)}

In situ heating experiments of two-phase alloys performed inside a TEM indicate that the motion of dislocations often involve climb besides glide (Appel, 2001; Anton et al., 1989). This is often ascribed to the processing routes of these materials that involve thermomechanical treatments and rapid quenches. During in situ heating experiments, the dislocations moved under the combined action of thermomechanical stresses and osmotic climb forces. The occurrence of dislocation climb requires a very compact core structure for the dislocation (Hirth and Lothe, 1982). To achieve a compact core for the dislocation $b_{1}=[001]$ on (110), a pair of dislocation dipole is introduced in a simulation cell where the repulsive interaction force will condense the extended core of the dislocation (Chu et al., 2012; Wang et al., 2001), in turn, favor dislocation climb.

Figure 10a shows the simulation cell that contains two full dislocations with opposite signed Burgers vectors. A full dislocation with the Burgers vector [001] is dissociated into two partials (marked as 1 and 2) with the same Burgers vector $1 / 2[001]$ that are positioned at the left of the simulation cell $(\mathrm{x}=-13.2 \mathrm{~nm})$, and another full dislocation with the Burgers vector [001] is dissociated with into two partials (marked as 3 and 4) with the same Burgers vector 1/2[001] that are positioned at the right of the simulation cell $(x=13.2 \mathrm{~nm})$. They initially separated from a distance of $26.4 \mathrm{~nm}$ in the $\mathrm{x}$-direction. The left full dislocation is gliding on the shear plane of $\mathrm{Al}_{\mathrm{C}}-\mathrm{Al}_{\mathrm{D}}$ (see Figure $2 \mathrm{a}$ ), and the right one is gliding on the shear plane of $\mathrm{Al}_{\mathrm{B}}-\mathrm{Al}_{\mathrm{A}}$ (see Figure $2 \mathrm{a}$ ). They are 
separated for $0.28 \mathrm{~nm}$ in the $\mathrm{y}$-direction, corresponding to three atomic planes $\mathrm{Al}_{\mathrm{A}} \mathrm{CuAl}_{\mathrm{C}}$. The periodic boundary condition is applied along the z-axis. The temperature is initially set up at $300 \mathrm{~K}$. During MD simulation, the temperature control is accomplished by applying the Langevin force to atoms. The position of the two dislocations at each moment is determined by the disregistry analysis. We accelerate the dislocations by homogeneously straining the entire simulation model with a constant shear strain rate $\dot{\gamma}_{y x}=2 \times 10^{8} \mathrm{~s}^{-1}$.

The intriguing finding from MD simulations is dislocation climb accompanying the creation of vacancies. Figure 10b shows the climb of partial dislocation 3 upwards for four atomic planes $\left(\mathrm{Al}_{\mathrm{A}} \mathrm{CuAl}_{\mathrm{C}} \mathrm{Al} \mathrm{D}_{\mathrm{D}}\right)$. This climb motion will create vacancies corresponding to its Burgers vector and climb direction. The partial dislocation 3 now glides on the shear plane of $\mathrm{Al}_{\mathrm{D}}-\mathrm{Al}_{\mathrm{C}}$. After the climb, the two partials 3 and 4 (separated for 4 atomic planes) glide together. Figure 10c shows the climb of partial dislocation 1 downwards for four atomic planes $\left(\mathrm{Al}_{C} \mathrm{CuAl}_{\mathrm{A}} \mathrm{Al}_{\mathrm{B}}\right)$. This climb motion will create vacancies corresponding to its Burgers vector and climb direction. The partial dislocation 1 now glides on the shear plane of $\mathrm{Al}_{\mathrm{A}}-\mathrm{Al}_{\mathrm{B}}$. After the climb, two partials 1 and 2 (separated for 4 atomic planes) glide together. Interestingly, none of the four partials glides on the same shear plane. Partials 1 and 4 are separated for one $\mathrm{Al}_{\mathrm{B}}$ plane, and partials 2 and 3 are separated for one $\mathrm{Al}_{\mathrm{D}}$ plane. Figure $10 \mathrm{~d}$ shows the annihilation of four partials. The applied shear stress and their interaction forces drive the glide and climb of dislocations. The interaction force (parallel to the glide plane) between two non-coplanar dislocations change from attraction to repulsion at a certain distance, the repulsive force impedes the motion of the leading partial and consequently condenses the extended core. The interaction force (perpendicular to the glide plane) between two non-coplanar dislocations is always attractive, and facilitates dislocation climb by re-dissociating the condensed core into a vertical-extended core.

Figure 11 shows the planar extended core, the vertical extended core after one partial climbs, and the collective glide of the two partials. Accompanying the climb, Figure 11d shows the created 18 vacancies (12 vacancies in Al planes and 6 vacancies in $\mathrm{Cu}$ plane). It is worth mentioning that the collective glide of the two vertical pile-up partials did not create stacking faults (Figure 10c and Figure 10d) in the sheared regions, 
implying that the collective glide is associated with atomic shuffle (Chu and Pope, 1993; Hirth et al., 2016). Figure 12a shows the position and velocity of the two full dislocations as a function of time, and Figure 12b shows the shear stress as a function of time. It clearly shows a full dislocation (the left dislocation) with the planar extended core glides faster than the dislocation (the right dislocation) with the vertical extended core. The first climb occurs at the shear stress of $1.6 \mathrm{GPa}$, and the separation is about $8 \mathrm{~nm}$. When the two sets of dislocations are close at the distance of $2 \mathrm{~nm}$, the annihilation occurs immediately, corresponding to athermal process.

\section{Conclusions}

Using atomistic simulations, we studied dislocation mobility on slip systems $\left.(110)\langle 001\rangle, \quad(010)<001\rangle,(310)<001\rangle,(010)<100\rangle,(110)<1 \overline{1} 0\rangle,(110) \frac{1}{2}<1 \overline{1} 1\right\rangle$ and (112) $\frac{1}{2}<\overline{1} \overline{1} 1>$ in $\mathrm{Al}_{2} \mathrm{Cu}$. We found that three edge dislocations with Burgers vector $<001>$ on glide planes (110), (010), and (310), show an extended core. MD simulations further demonstrated motion of these dislocations at room and moderate temperature. Other four edge dislocations associated with slip systems $\left.(010)<100\rangle,(110)<1 \overline{1} 0\rangle,(110) \frac{1}{2}<1 \overline{1} 1\right\rangle$ and $(112) \frac{1}{2}\langle\overline{1} 11\rangle$, and three screw dislocations with Burgers vectors $\langle 001\rangle,\langle 110\rangle$, and $1 / 2<111>$ show a condensed core, and do not glide at room temperature. These observations are in agreement with experiments and consistent with the feature of dislocation cores - the glide of a dislocation experiences lower friction force when the dislocation has a wider, planar core. Furthermore, we investigated interaction of dislocation dipole and found that the extended-core dislocation associated slip system $(110)<001>$ climb at room temperature through three stages: the extended core condenses as the $\mathrm{P}-\mathrm{K}$ force acting on the leading partial decreases, the leading partial dislocation climbs accompanying the creation of vacancies (resulting in a non-planar core), and the two partials with non-planar core can glide together on the neighboring slip planes in association with atomic shuffles.

The knowledge of slip systems is the essential fundamentals for understanding mechanical behaviors and developing materials modeling tools at high length scales, such as discrete dislocation dynamics and crystal plasticity models [Ghoniem et al., 2000; Zbib 
and Khraishi, 2005; Diard et al., 2005]. The creation of vacancies associated with the relatively easy dislocation climb could account for structural instability of $\theta-\mathrm{Al}_{2} \mathrm{Cu}$ and poor deformability. Experimental studies revealed the selective dissolution of Al from $\theta$ $\mathrm{Al}_{2} \mathrm{Cu}$, and suggested that crystallographic defects, such as stacking faults and dislocations, facilitate de-alloying of $\theta-\mathrm{Al}_{2} \mathrm{Cu}$ [Zhang et al., 2016; Lebouil et al., 2014; Hashimoto et al., 2016]. The planar-extended dislocation is comprised of two partials and one stacking fault. The fault region could operate as precursor for de-alloying of $\theta-\mathrm{Al}_{2} \mathrm{Cu}$ because of the increased local stored energy. Moreover, dislocation dipole interaction results in dislocations climb associated with the creation of vacancies, consequently, the high population of vacancies facilitate the diffusion of the alloying element atoms, thus accelerating de-alloying of $\mathrm{Al}$ from $\theta-\mathrm{Al}_{2} \mathrm{Cu}$. The easy climb of dislocations driven by dislocations interaction will reduce the glide ability, limiting plastically shear deformation under mechanical loading. Further experimental study is thus needed to clarify these.

Acknowledgements: JW and AM acknowledge research sponsorship by DOE, Office of Basic Energy sciences. PH acknowledges research sponsorship by the National Natural Science Foundation of China (51171141 and 51471131), and FW acknowledges research sponsorship by the National Natural Science Foundation of China (51271141).

\section{References}

Anton, D.L., Shah, D.M., Duhl, D.N., Giamei, A.F., 1989. Selecting high-temperature structural intermetallic compounds: the engineering approach. JOM 41, 12-17.

Apostol, F., Mishin, Y., 2011. Interatomic potential for the Al-Cu system. Phys. Rev. B $83,054116$.

Appel, F., 2001. Diffusion assisted dislocation climb in intermetallic gamma TiAl. Mater. Sci. Eng. A 317, 115-127.

Barnett, D. M., Lothe, J., (1974). An image force theorem for dislocations in bicrystals. J. Phys. F. 4, 1618-1635.

Bonnet, R., 2002a. HRTEM Observation of a <113> Low Angle Tilt Boundary in the Al$\mathrm{Al} 2 \mathrm{Cu}(\theta)$ Eutectic Composite. Phys. Stat. Sol.(a) 189, 183-196.

Bonnet, R., Loubradou, M., 2002b. Crystalline defects in a $\mathrm{BCT} \mathrm{Al}_{2} \mathrm{Cu}(\theta)$ single crystal obtained by unidirectional solidification along [001]. Phys. Stat. Sol. (a) 194, 173191.

Chadwick, G.A., 1963. Eutectic alloy solidification. Prog. Mater. Sci. 12, 99-182.

Chanda, T., Murty, G.S., 1992. Plastic behaviour of CuAl2. J. Mater. Sci. 27, 5931-5934. 
Chen, D., Ma, X.L., 2013. Local decomposition induced by dislocation motions inside tetragonal A12Cu compound: slip system-dependent dynamics. Sci. Rep. 3, 3157.

Chu, F., Pope, D.P., 1993. Deformation twinning in intermetallic compounds-the dilemma of shears vs. shuffles. Mater. Sci. Eng. A 49, 39-47.

Chu, H.J., Wang, J., Beyerlein, I.J., 2012. Anomalous reactions of a supersonic coplanar dislocation dipole: Bypass or twinning? Scr. Mater. 67, 69-72.

Csontos, A.A., Starke, E.A., 2005. The effect of inhomogeneous plastic deformation on the ductility and fracture behavior of age hardenable aluminum alloys. Int. J. Plast. 21, 1097-1018.

Diard, O., Leclercq, S., Rousselier, G., Cailletaud, G., (2005). Evaluation of finite element based analysis of 3D multicrystalline aggregates plasticity: Application to crystal plasticity model identification and the study of stress and strain fields near grain boundaries. Int. J. Plasticity 21(4), 691-722.

Eckert, J., Schultz, L., Urban, K., 1991. Formation of quasicrystalline and amorphous phases in mechanically alloyed Al-based and Ti Ni-based alloys. Acta Metall. Mater. 39, 1497-1506.

Embury, J.D., Hirth. J.P., 1994. On dislocation storage and the mechanical response of fine scale microstructures. Acta Metall. Mater. 42, 2051-2056.

Fribourg-Blanc, N., Dupeux, M., Guenin, G., Bonnet, R., 1979. Determination by Extensometry and Ultrasonic Measurements of the Six Elastic Constants of thetaAl2Cu Crystals: Anisotropy. J. Appl. Crystall. 12, 151-155.

Gao, K., Li, S.M., Xu, L., Fu, H.Z., 2014. Effect of sample size on intermetallic Al2Cu microstructure and orientation evolution during directional solidification. J. Cryst. Growth. 394, 89-96.

Ghoniem, N.M., Tong, S.-H. and Sun, L.Z., (2000). Parametric dislocation dynamics: a thermodynamics-based approach to investigations of mesoscopic plastic deformation. Phys. Rev. B 61(2), 913-927.

Gridnev, V.N., Gavrilyuk, V.G., 1982. Cementite Decomposition in Steel During Plastic Deformation. (Review). Phys. Met. (USSR) 4, 531-551.

Han, C.S., Wagoner, R.H., Barlat, F., 2004. On precipitate induced hardening in crystal plasticity theory. Int. J. Plast. 20, 477-494.

Hales, S.J., McNelley, T.R., 1988. Microstructural evolution by continuous recrystallization in a superplastic Al-Mg alloy. Acta Metall. 36, 1229-1239.

Hashimoto, T., Zhang, X., Zhou, X., Skeldon, P., Haigh, S.J., Thompson, G.E., 2016. Investigation of dealloying of $\mathrm{S}$ phase $\left(\mathrm{Al}_{2} \mathrm{CuMg}\right)$ in $\mathrm{AA} 2024-\mathrm{T} 3$ aluminium alloy using high resolution 2D and 3D electron imaging. Corros. Sci. 103, 157-164.

Henkelman, G., Jónsson, H., 2000. Improved tangent estimate in the nudged elastic band method for finding minimum energy paths and saddle points, J. Chem. Phys. 113, 9978-9985.

Hirth, J.P., Lothe, J., 1982. Theory of dislocations.

Hirth, J.P., Wang, J., Tomé, C.N., 2016. Disconnections and Other Defects associated with Twin Interfaces. Prog. Mater. Sci. doi:10.1016/j.pmatsci.2016.07.003. 
Howe, J.M., Benson, W.E., Garg, A., Chang, Y.C., 1995. In Situ Hot-Stage HighResolution Transmission Electron Microscopy of Interface Dynamics during Growth and Dissolution of (111) a $\mathrm{O}-\mathrm{Al} 2 \mathrm{Cu}$ Plates in an Al-Cu-Mg-Ag Alloy. Mater. Sci. Forum. Trans Tech Publications. 189, 255-260.

Ignat, M., Bonnet, R., Caillard, D., Martin, J.L., 1978. Creep of the lameller Al-CuAl2 composite I. Microstructural observations. Phys. Stat. Sol. (a) 49, 675-684.

Ignat, M., Durand, F., 1976. Deformation lines on Al2Cu single crystals after creep in compression. Scr. Metall. 10, 623-626.

Inoue, A., 1998. Amorphous, nanoquasicrystalline and nanocrystalline alloys in Al-based systems. Prog. Mater. Sci. 43, 365-520.

Jobba, M., Mishra, R.K., Niewczas, M., 2015. Flow stress and work-hardening behaviour of Al-Mg binary alloys. Inter. J. Plast. 65, 43-60.

Khan, A.S., Liu, H., 2012. A new approach for ductile fracture prediction on Al 2024T351 alloy. Int. J. Plast. 35, 1-2.

Knowles, K.M., Stobbs, W.M., 1988. The structure of $\{111\}$ age-hardening precipitates in $\mathrm{Al}-\mathrm{Cu}-\mathrm{Mg}-\mathrm{Ag}$ alloys. Acta Crystall. Section B: Struct. Sci. 44, 207-227.

Korznikov, A.V., Dimitrov, O., Korznikova, G.F., Dallas, J.P., Quivy, A., Valiev, R.Z., et $a l, 1999$. Nanocrystalline structure and phase transformation of the intermetallic compound TiAl processed by severe plastic deformation. Nanostruct. Mater. 11, 1723.

Lebouil, S., Tardelli, J., Rocca, E., Volovitch, P., Ogle, K., 2014. Dealloying of Al2 Cu, $\mathrm{A} 17 \mathrm{Cu} 2 \mathrm{Fe}$, and $\mathrm{Al} 2 \mathrm{CuMg}$ intermetallic phases to form nanoparticulate copper films. Mater. Corros. 65, 416-424.

Li, B.Q., Wawner, F.E., 1998. Dislocation interaction with semicoherent precipitates $(\Omega$ phase) in deformed $\mathrm{Al}-\mathrm{Cu}-\mathrm{Mg}-\mathrm{Ag}$ alloy. Acta Mater. 46, 5483-5490.

Li, N., Wang, H., Misra, A., Wang, J., 2014. In situ Nanoindentation Study of Plastic Codeformation in Al-TiN Nanocomposites. Sci. Rep. 4, 6633.

Liu, G., 2011. Time-resolved and three-dimensional study of dislocation-particle interactions in aluminum and copper alloys. University of Illinois at UrbanaChampaign.

Liu, L., Wang, J., Gong, S.K., Mao, S.X., 2011. High resolution transmission electron microscope observation of zero-strain deformation twinning mechanisms in Ag. Phys. Rev. Lett. 106, 175504.

Loucif, A., Figueiredo, R.B., Baudin, T., Brisset, F., Langdon, T.G., 2010. Microstructural evolution in an Al-6061 alloy processed by high-pressure torsion. Mater. Sci. Eng. A 527, 4864-4869.

Mabuchi, M., Higashi, K., 2001. An experimental investigation of a superplastic constitutive equation in $\mathrm{Al}-\mathrm{Mg}-\mathrm{Si}$ alloy composites reinforced with Si3N4 whiskers. Int. J. Plast. 17, 399-407.

Muñoz-Morris, M.A., Gutierrez-Urrutia, I., Morris, D.G., 2009. Influence of nanoprecipitates on the creep strength and ductility of a Fe-Ni-Al alloy. Int. J. Plast. $25,1011-1023$. 
Murayama, M., Horita, Z., Hono, K., 2001. Microstructure of two-phase Al-1.7at\%Cu alloy deformed by equal-channel angular pressing. Acta Mater. 49, 21-29.

Nie, J.F., Muddle, B.C.,2000. Comments on the "dislocation interaction with semicoherent precipitates ( $\omega$ phase) in deformed Al-Cu-Mg-Ag alloy". Scr. Mater. 42, 409-413.

Nogita, K., Yasuda, H., Yoshida, K., Uesugi, K., Takeuchi, A., Suzuki, Y., 2006. Determination of strontium segregation in modified hypoeutectic Al-Si alloy by micro X-ray fluorescence analysis. Scr. Mater. 55, 787-790.

Otsuka, K., Shimizu, K., 1970. Memory effect and thermoelastic martensite transformation in CuAlNi alloy. Scr. Metall. 4, 469-472.

Prados, V.L., Sordi, E.F., Ferrante, M., 2013. The effect of Al2Cu precipitates on the microstructural evolution, tensile strength, ductility and work-hardening behaviour of a Al-4 wt.\% Cu alloy processed by equal-channel angular pressing. Acta Mater. 61, $115-125$.

Park, J.M., Mattern, N., Kühn, U., Eckert, J., Kim, K.B., Kim, W.T., 2009 High-strength bulk Al-based bimodal ultrafine eutectic composite with enhanced plasticity. J. Mater. Res. 24, 2605-2609.

Park, J.M., Kim, K.B., Kim, D.H., Mattern, N., Li, R., Liu, G., Eckert, J., 2010. Multiphase Al-based ultrafine composite with multi-scale microstructure. Intermetallics. $18,1829-1833$.

Pérez-Prado, M.T., Ruano, O.A., 2004. Grain refinement of $\mathrm{Mg}-\mathrm{Al}-\mathrm{Zn}$ alloys via accumulative roll bonding. Scr. Mater. 51, 1093-1097.

Picu, R.C., Vincze, G.T., Gracio, J.J., 2011. Deformation and microstructure-independent Cottrell-Stokes ratio in commercial Al alloys. Int. J. Plast. 27, 1045-1054.

Rajan, T.P.D., Pillai, R.M., Pai, B.C., 2008. Functionally graded Al-Al3Ni in situ intermetallic composites: fabrication and microstructural characterization. J. Alloy. Compd. 453, L4-L7.

Russell, K.C., Ashby, M.F., 1970. Slip in aluminum crystals containing strong, plate-like particles. Acta. Metall. 18, 891-901.

Salehinia, I., Shao, S., Wang, J., Zbib, H.M., 2015. Interface structure and the inception of plasticity in $\mathrm{Nb} / \mathrm{NbC}$ nanolayered composites. Acta. Mater. 86, 331-340.

Salehinia, I., Shao, S., Wang, J., Zbib, H.M., 2014. Plastic Deformation of Metal/Ceramic Nanolayered Composites. JOM. 66, 2078-2085.

Schroll, R., Vitek, V., Gumbsch, P., 1998. Core properties and motion of dislocations in NiAl. Acta. Mater. 46, 903-918.

Shao, S., Wang, J., Beyerlein, I.J., Misra, A., 2015. Glide dislocation nucleation from dislocation nodes at semi-coherent $\{111\} \mathrm{Cu}-\mathrm{Ni}$ interfaces. Acta. Mater. 98, 206-220.

Shield, T.W., 1995 Orientation dependence of the pseudoelastic behavior of single crystals of CuAlNi in tension. J. Mech. Phys. Solids. 43, 869-895.

Tao, J., Yang, K., Xiong, H., Wu, X., Zhu, X., Wen, C., 2013. The defect structures and mechanical properties of $\mathrm{Cu}$ and $\mathrm{Cu}-\mathrm{Al}$ alloys processed by split Hopkinson pressure bar. Mater. Sci. Eng. A, 580, 406-409. 
Trivedi, P., Field, D.P., Weiland, H., 2004. Alloying effects on dislocation substructure evolution of aluminum alloys. Int. J. Plast. 20, 459-476.

Uenishi, K., Kobayashi, K.F., Ishihara, K.N., Shingu, P.H., 1991. Formation of a supersaturated solid solution in the Ag Cu system by mechanical alloying. Mater. Sci. Eng. A $134,1342-1345$.

Umakshi, Y., 1993. Deformation of Intermetallic Compounds, in Materials Science and Technology: A Comprehensive Treatment, Vol. 6, Plastic Deformation and Fracture of Materials, R.W. Cahn, P. Haasen and E.J. Kramer editors, (VCH Publishers, New York) Ch. 6, 251-310.

Valiev, R.Z., Islamgaliev, R.K., Alexandrov, I.V., 2000. Bulk nanostructured materials from severe plastic deformation. Prog. Mater. Sci. 45, 103-189.

Wang, J., Zhang, R.F., Zhou, C.Z., Beyerlein, I.J., Misra, A., 2014a. Interface dislocation patterns and dislocation nucleation in face-centered-cubic and body-centered-cubic bicrystal interfaces. Int. J. Plast. 53, 40-55.

Wang, J., Misra, A., 2014b. Strain hardening in nanolayered thin films. Curr. Opin. Solid St. Mater. Sci. 18, 19-28.

Wang, J., Misra, A., Hoagland, R.G., Hirth, J.P., (2012). Slip transmission across fcc/bcc interfaces with varying interface shear strengths. Acta Mater. 60 (4), 1503-1513.

Wang, J., Hoagland, R.G., Liu, X.Y., Misra, A., 2011a. The influence of interface shear strength on the glide dislocation-interface interactions. Acta. Mater. 59, 3164-3173.

Wang, J., Beyerlein, I.J., Hirth, J.P., Tomé, C.N., 2011b. Twinning dislocations on \{$1011\}$ and $\{-1013\}$ planes in hexagonal close-packed crystals. Acta. Mater. 59, 39904001.

Wang, J., Li, N., Anderoglu, O., Zhang, X., Misra, A., Huang, J.Y., Hirth, J.P., 2010. Detwinning mechanisms for growth twins in face-centered cubic metals. Acta. Mater. 58, 2262-2270.

Wang, J., Li, N., Misra, A., 2013. Structure and stability of $\Sigma 3$ grain boundaries in face centered cubic metals. Philo. Mag. 93, 315-327.

Wang, J., Hoagland, R.G., Hirth, J.P., Misra, A., 2008. Atomistic modeling of the interaction of glide dislocations with "weak" interfaces. Acta. Mater. 56, 5685-5693.

Wang, J., Woo, C.H., Huang, H., 2001. Destabilization of dislocation dipole at high velocity. Appl. Phys. Lett. 79, 3621-3623.

Witkin, D., Lee, Z., Rodriguez, R., Nutt, S., Lavernia, E., 2003. Al-Mg alloy engineered with bimodal grain size for high strength and increased ductility. Scr. Mater. 49, 297302.

Yanilkin, A.V., Krasnikov, V.S., Kuksin, A.Y., Mayer, A.E., 2014. Dynamics and kinetics of dislocations in $\mathrm{Al}$ and $\mathrm{Al}-\mathrm{Cu}$ alloy under dynamic loading. Int. J. Plast. 55, 94-107.

Yang, B., Zhou, Y.T., Chen, D., Ma, X.L., 2013. Local decomposition induced by dislocation motions inside precipitates in an Al-alloy. Sci. Rep. 3, 1039.

Youssef, K.M., Scattergood, R.O., Murty, K.L., Koch, C.C., 2006. Nanocrystalline Al$\mathrm{Mg}$ alloy with ultrahigh strength and good ductility. Scr. Mater. 54, 251-256. 
Zbib, H.M. and Khraishi, T.A., (2005). Dislocation Dynamics. In Handbook of Materials Modeling, edited by S Yip. 1097-1114.

Zhang, X., Hashimoto, T., Lindsay, J., Zhou, X., 2016. Investigation of the de-alloying behaviour of $\theta$-phase $\left(\mathrm{Al}_{2} \mathrm{Cu}\right)$ in AA2024-T351 aluminium alloy. Corros. Sci. 108, 85-93.

Zheng, S., Beyerlein, I.J., Carpenter, J.S., Kang, K., Wang, J., Han, W., et al, 2013. Highstrength and thermally stable bulk nanolayered composites due to twin-induced interfaces. Nature. Commun. 4, 1696

Zhou, F., Liao, X.Z., Zhu, Y.T., Dallek, S., Lavernia, E.J., 2003. Microstructural evolution during recovery and recrystallization of a nanocrystalline $\mathrm{Al}-\mathrm{Mg}$ alloy prepared by cryogenic ball milling. Acta. Mater. 51, 2777-2791. 


\section{Figures Captions}

Figure 1. Simulation cell. The periodic boundary is applied along the z-axis.

Figure 2. Atomic structures of the projection of a unit cell along (a) $\langle 1 \overline{1} 0\rangle$ and (b) $<110\rangle$. One periodic (110) plane contains eight atomic planes with the stacking sequence: $\mathrm{CuAl}_{\mathrm{A}} \mathrm{Al}_{\mathrm{B}} \mathrm{Al}_{\mathrm{A}} \mathrm{CuAl}_{\mathrm{C}} \mathrm{Al}_{\mathrm{D}} \mathrm{Al}_{\mathrm{C}}$. The relative position of atoms in the stack is shown in (b). The blue rectangles outline the unit cell on the projected plane. Three dislocations: $\mathbf{b}_{1}=\langle 001\rangle, \mathbf{b}_{2}=\frac{1}{2}\langle\overline{1} \overline{1} 1\rangle$, and $\mathbf{b}_{3}=\langle 1 \overline{1} 0\rangle$, are denoted in figure 3 .

Figure 3. Energy surfaces of shear planes between $\mathrm{Cu}-\mathrm{Al}_{\mathrm{A}}$ (a) and $\mathrm{Al}_{\mathrm{B}}-\mathrm{Al}_{\mathrm{A}}(\mathrm{b})$, and three possible shears associated with three lattice dislocations: $\mathbf{b}_{1}=\langle 001\rangle, \mathbf{b}_{2}=\frac{1}{2}\langle\overline{1} \overline{1} 1\rangle$, and $\mathbf{b}_{3}=\langle 1 \overline{1} 0\rangle$. (c) Stacking fault energies associated with the shear along $\left.<001\right\rangle$ on the $\mathrm{Cu}-\mathrm{Al}_{\mathrm{A}}$ and $\mathrm{Al}_{\mathrm{B}}-\mathrm{Al}_{\mathrm{A}}$ planes, and (d) Stacking fault energies associated with the shear on the $\mathrm{Al}_{\mathrm{B}}-\mathrm{Al}_{\mathrm{A}}$ plane along three directions $\langle 001\rangle, \frac{1}{2}\langle\overline{1} \overline{1} 1\rangle$, and $\langle 1 \overline{1} 0\rangle$, respectively.

Figure 4. Atomic structures of a $<001>$ dislocation lying on (a) the $\mathrm{Al}_{\mathrm{B}}-\mathrm{Al}_{\mathrm{A}}$ shear plane and (b) the $\mathrm{Cu}-\mathrm{Al}_{\mathrm{A}}$ shear plane. Atoms are colored according to their excess potential energy. The thin black line indicates the slip plane. (c) Disregistry plots of the two dislocations, and (d) line energy of the two dislocations, showing that a $<001>$ dislocation lying on the $\mathrm{Al}_{\mathrm{B}}-\mathrm{Al}_{\mathrm{A}}$ shear plane has wider core and lower core energy. (e) Energy variation with the glide of a full dislocation [001] or a partial dislocation $1 / 2[001]$ on the $\mathrm{Al}_{\mathrm{B}}-\mathrm{Al}_{\mathrm{A}}$ shear plane, and (f) the generalized shear stress derived from the first derivative of the energy in (e).

Figure 5. Atomic structures of (a) a $\left.\frac{1}{2}<1 \overline{1} 1\right\rangle$ dislocation and (b) a $\langle 1 \overline{1} 0\rangle$ dislocation, that are on the $\mathrm{Al}_{\mathrm{B}}-\mathrm{Al}_{\mathrm{A}}$ shear plane. Atoms are colored according to their excess potential energy. The thin black line indicates the slip plane.

Figure 6. Atomic structures of the projection of a unit cell along (a) $<100>$ and (b) $<010\rangle$. One periodic (010) plane contains six atomic planes with the stacking sequence: $\mathrm{Cu}_{\mathrm{B}} \mathrm{Al}_{\mathrm{A}} \mathrm{Al}_{\mathrm{B}} \mathrm{Cu}_{\mathrm{A}} \mathrm{Al}_{\mathrm{C}} \mathrm{Al}_{\mathrm{D}} \mathrm{Cu}_{\mathrm{B}}$. The relative position of atoms in the stack is shown in (b). The blue rectangles outline the unit cell on the projected plane. (c) Energy surface of the $\mathrm{Cu}_{\mathrm{B}}-\mathrm{Al}_{\mathrm{A}}$ shear plane. Two possible shears associated with two 
lattice dislocations: $\mathbf{b}_{4}=<001>$ and $\mathbf{b}_{5}=<100>$ are denoted by the arrows. (d) Stacking fault energies with respect to the shear associated with the dislocations $\mathbf{b}_{4}=<001>$ and $\mathbf{b}_{5}=<100>$ on the $\mathrm{Cu}_{\mathrm{B}}-\mathrm{Al}_{\mathrm{A}}$ plane.

Figure 7. Atomic structure of a <001> dislocation with (a) condensed core and (b) extended core, and (c) of a $<100>$ dislocation with condensed core on the $\mathrm{Cu}_{\mathrm{B}^{-}}$ $\mathrm{Al}_{\mathrm{A}}$ plane. Atoms are colored according to their excess potential energy. The thin black line indicates the slip plane. (d) The change in the line energy of a <001> dislocation with respect to the separation distance between two partials.

Figure 8. Atomic structures showing the projections of a unit cell along (a) $<1 \overline{3} 0\rangle$ and (b) $<1 \overline{1} 0\rangle$. Blue atoms in (a) are $\mathrm{Cu}$, others are Al. (c) Atomic structure of a dislocation $b_{6}=<001>$ on the glide plane (310), and (d) Atomic structure of a dislocation $b_{7}=1 / 2<\overline{1} 11>$ on the glide plane (112). Atoms are colored according to their excess potential energy. Shear plane is in-between the stripes.

Figure 9. (a) Comparison of generalized stacking fault energies. Atomic structures of dislocations: (b) a screw dislocation $S_{1}$ with Burgers vector $\langle 001\rangle$, (c) a screw dislocation $S_{2}$ with Burgers vector $1 / 2<\overline{1} \overline{1} 1>$, and (d) a screw dislocation $\boldsymbol{S}_{3}$ with Burgers vector $<110\rangle$.

Figure 10. MD simulation of dislocation dipole interaction at temperature of $300 \mathrm{~K}$. (a) two full dislocations are separated about $25 \mathrm{~nm}$ along the horizontal direction and $0.28 \mathrm{~nm}$ along the vertical direction. (b) and (c) one partial climbs accompanying the creation of vacancies, and (d) dislocations annihilation. Atoms are colored according to their excess energy.

Figure 11. Atomic structures of two partials 3 and 4, showing (a) the planar extended core, (b) the climb of partial 3, (c) the collective glide of two partials. (d) Positions of the created vacancies as the partial 3 climbs and glides. Yellow atoms are $\mathrm{Cu}$ and grey atoms are $\mathrm{Al}$. The circle indicates location of the $\mathrm{i}^{\text {th }}$ vacancy.

Figure 12. (a) The position and velocity of the two full dislocations as a function of time, (b) the shear stress as a function of time. 


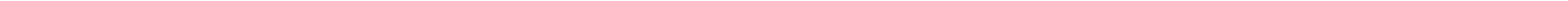

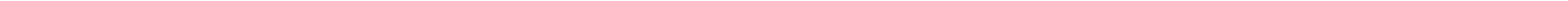

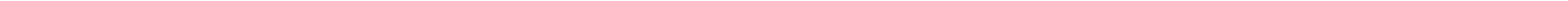

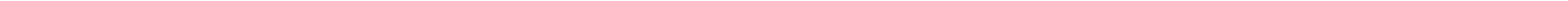

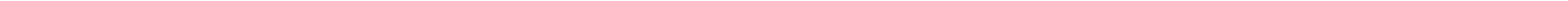

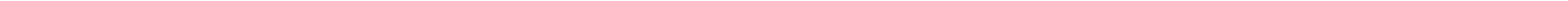

.

.

.

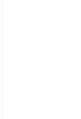

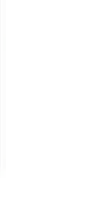

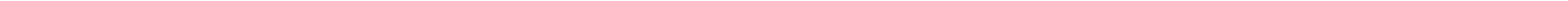

$\bar{y}$

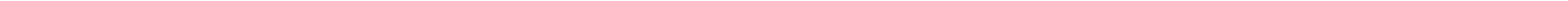




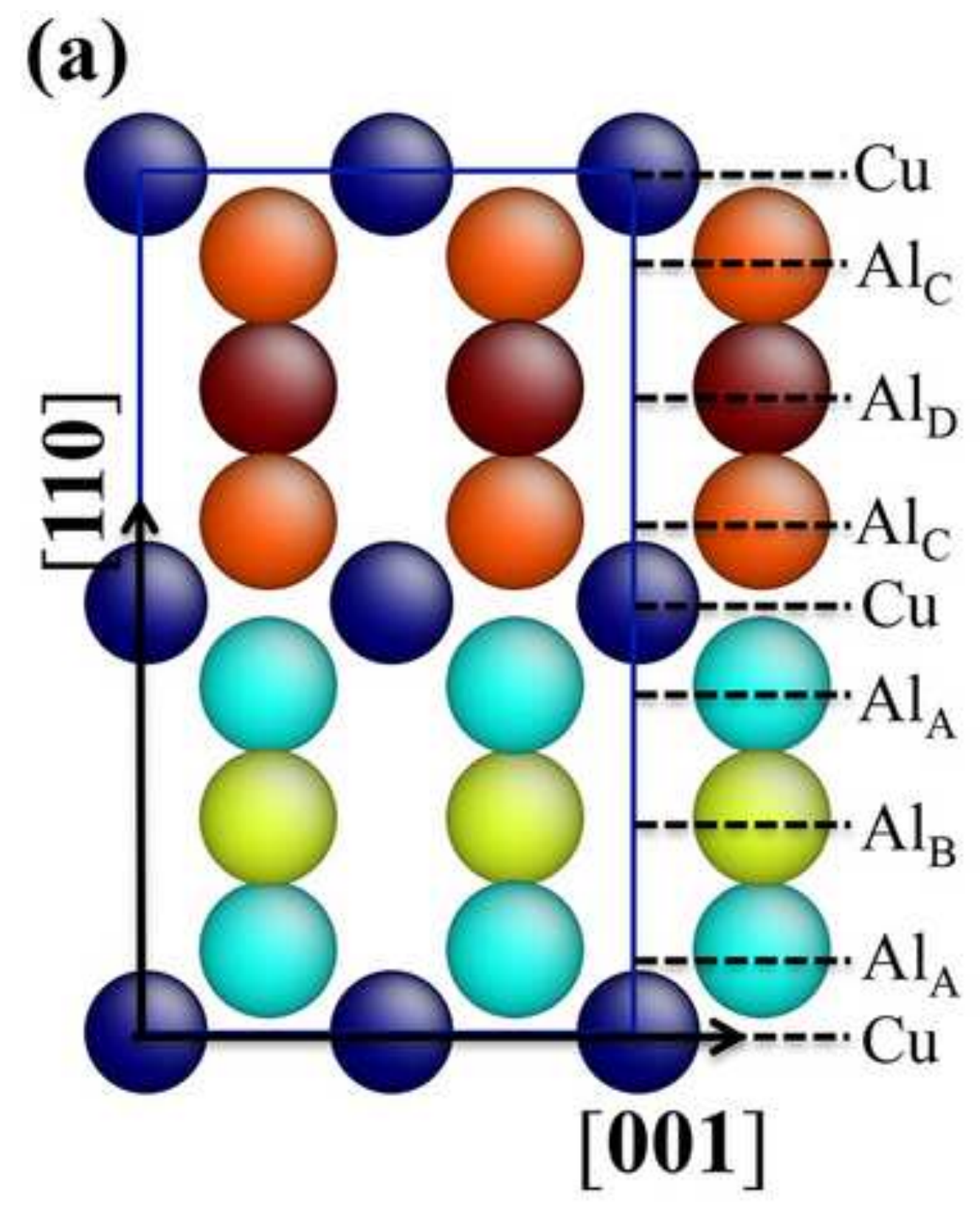

(a)

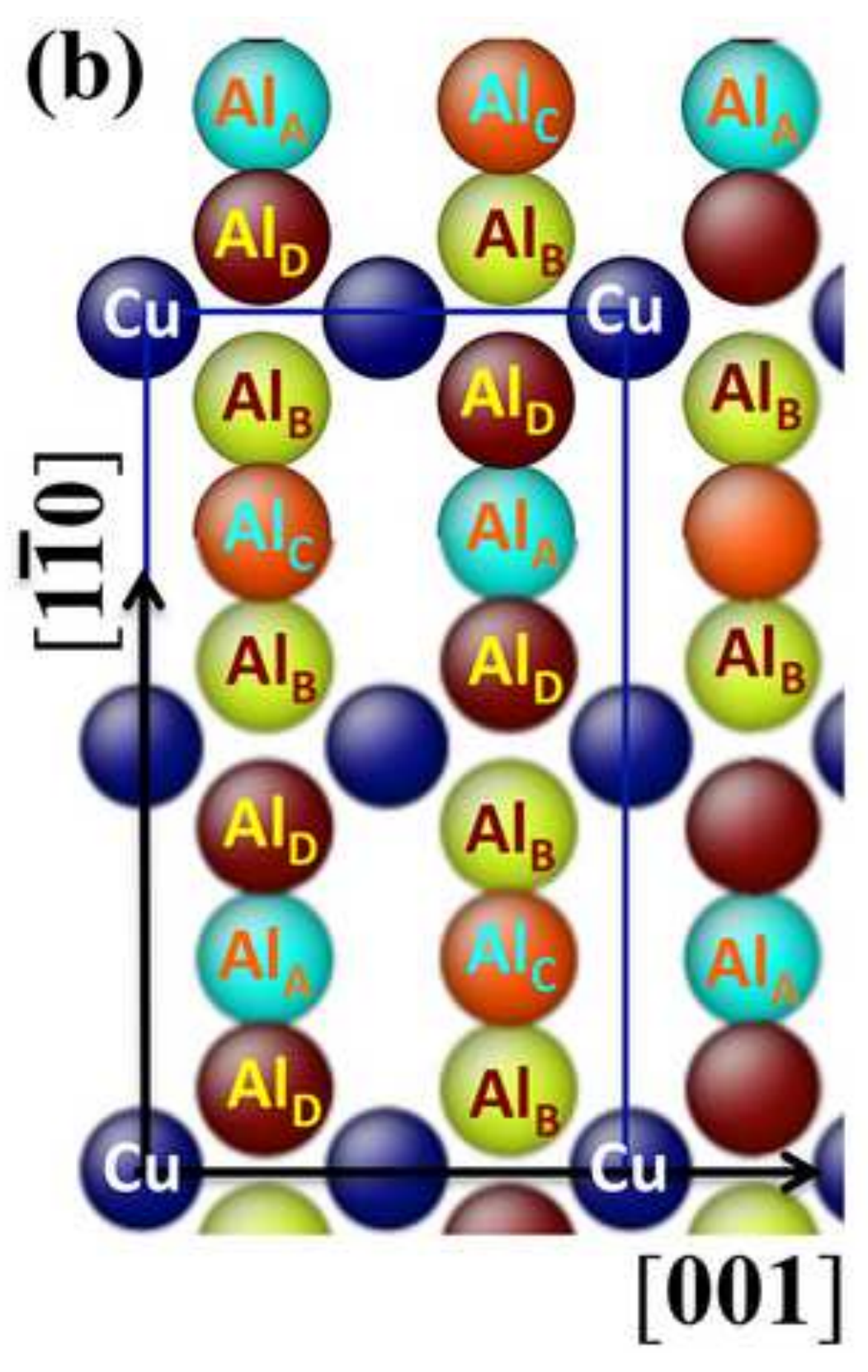



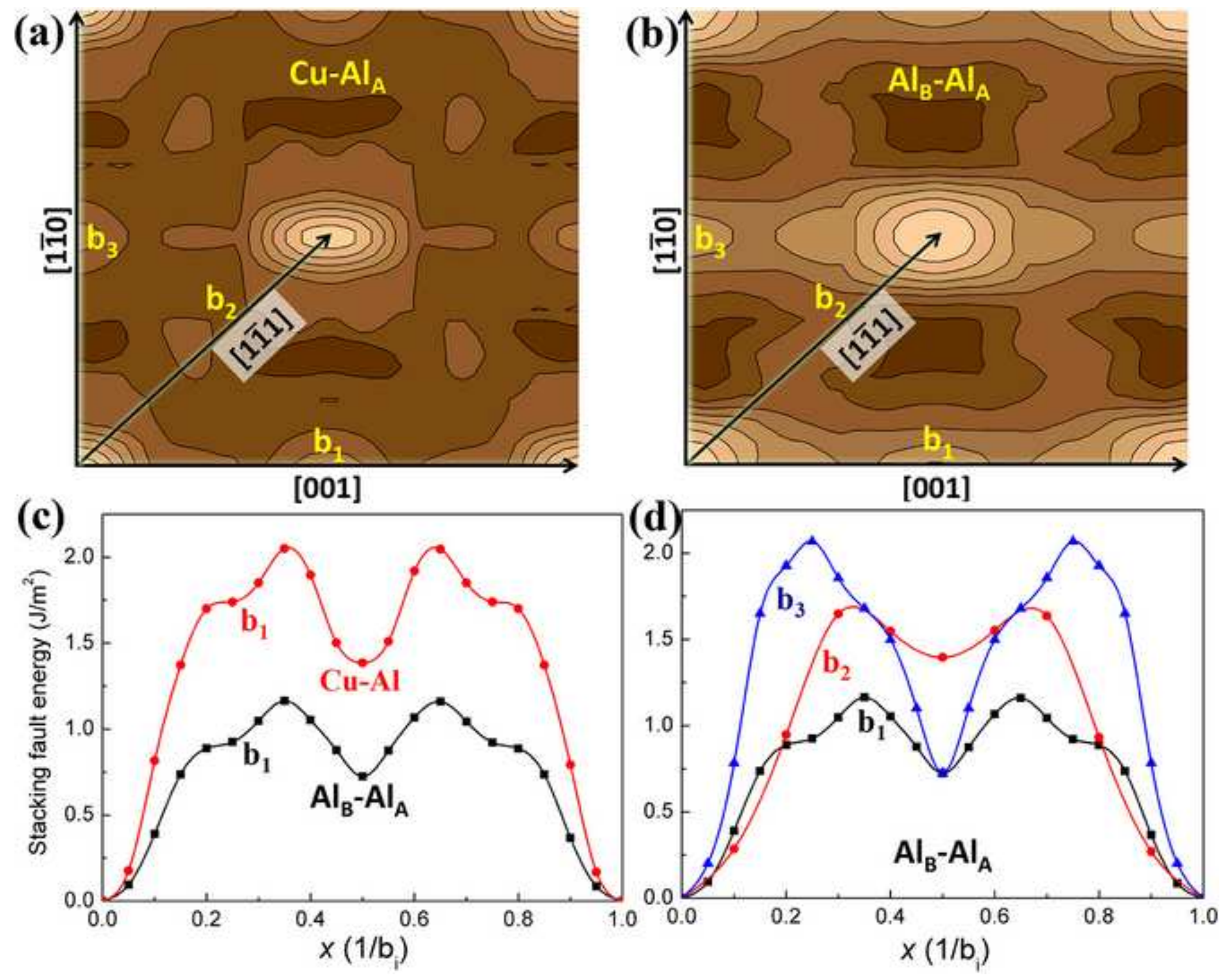

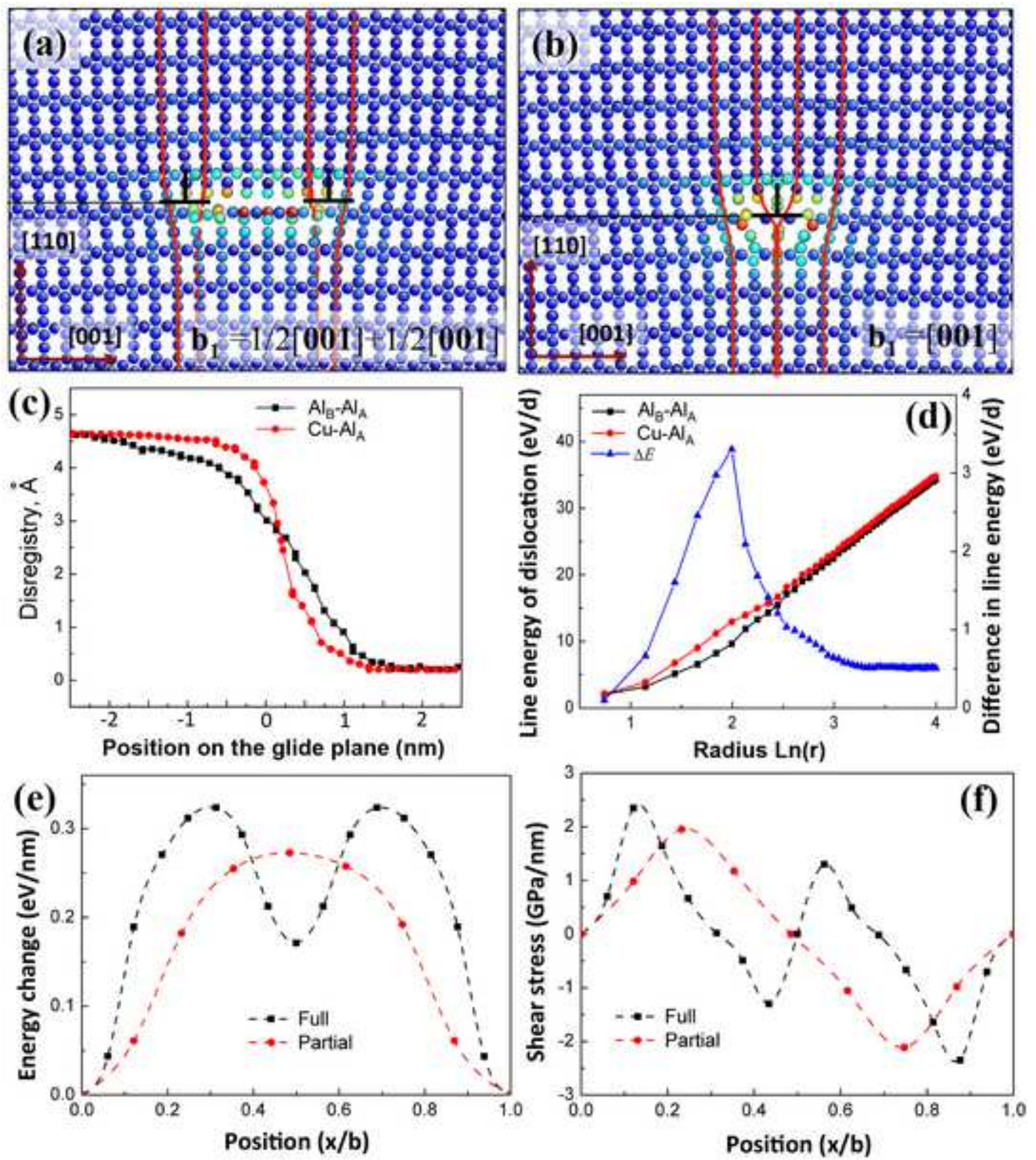

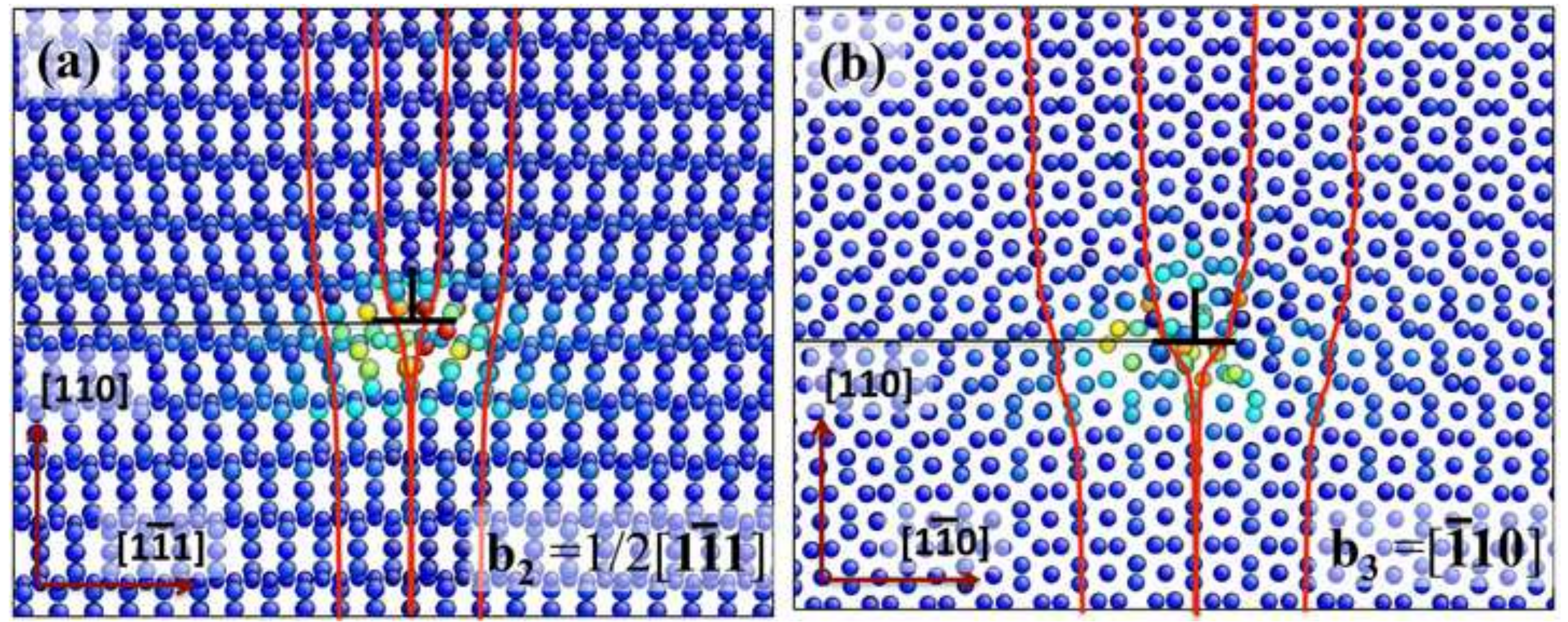
(a)

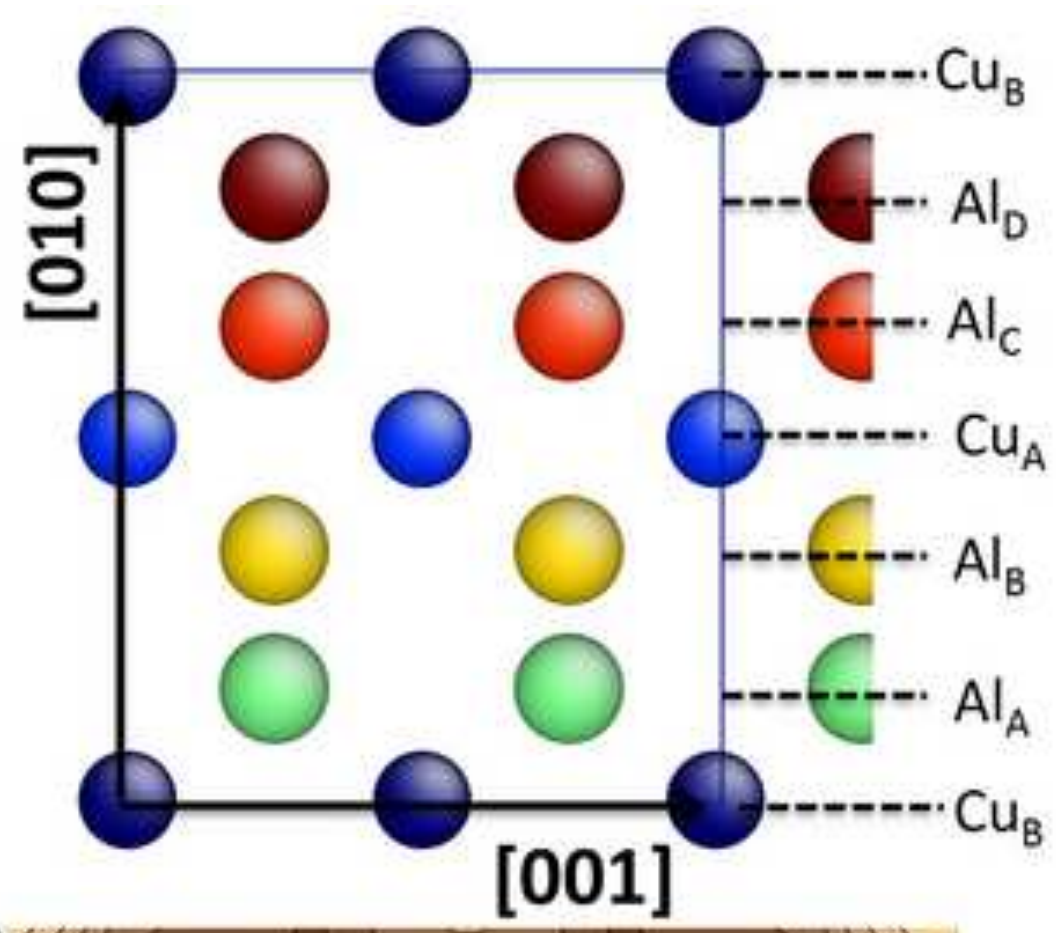

(b)

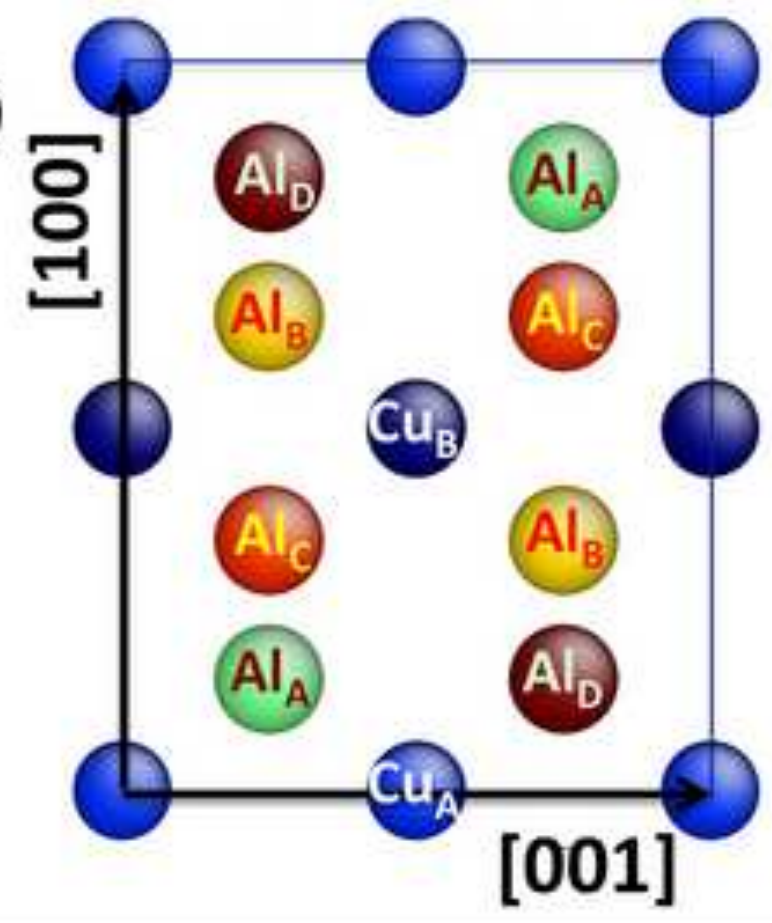

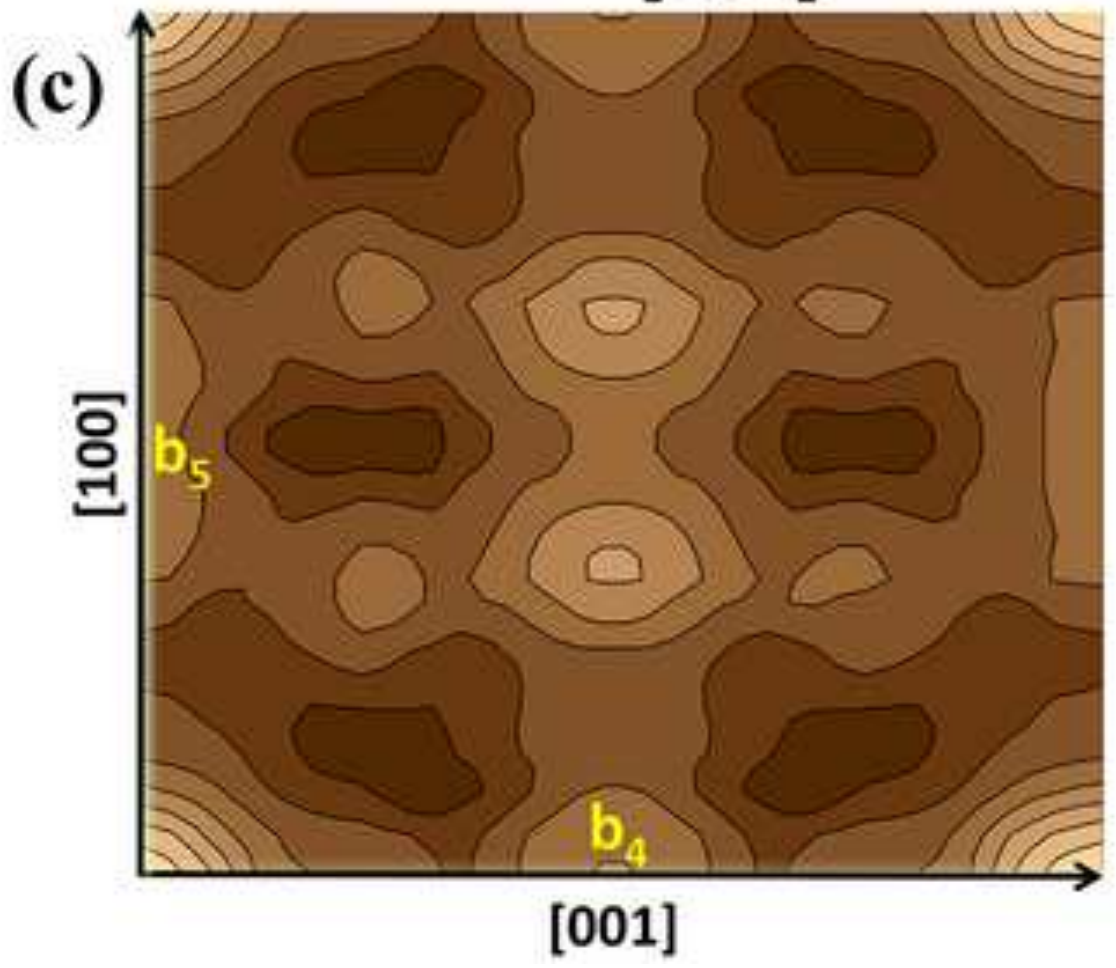

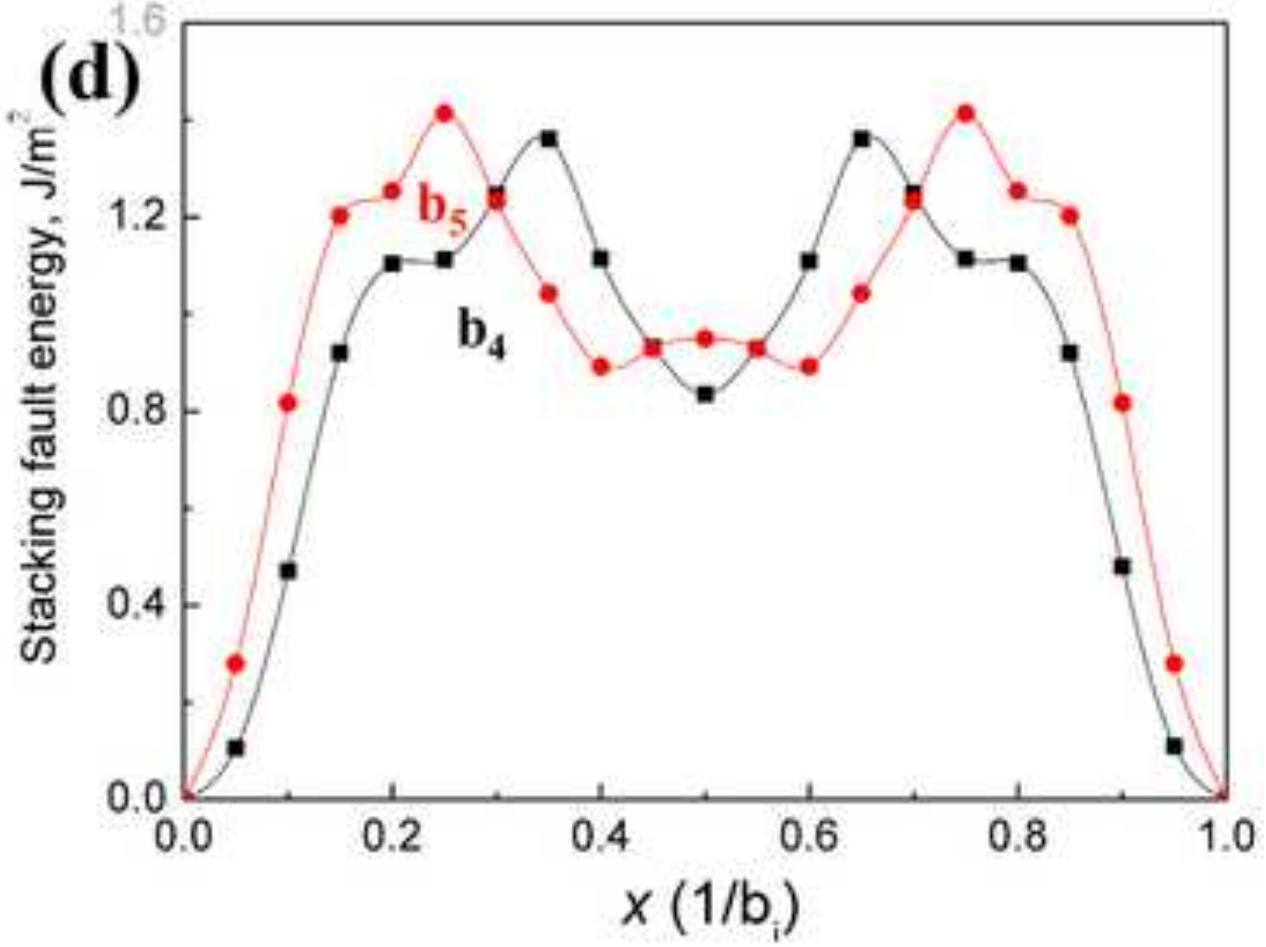


(a) $888 \% 8 \% 8 \% 8 \% 8 \% 8 \%$

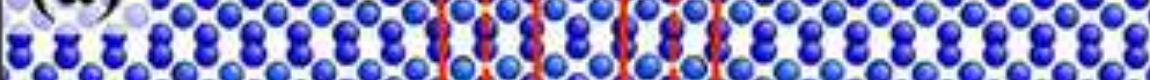
$88888888 \% 8 \% 8 \% 8 \% 8 \%$

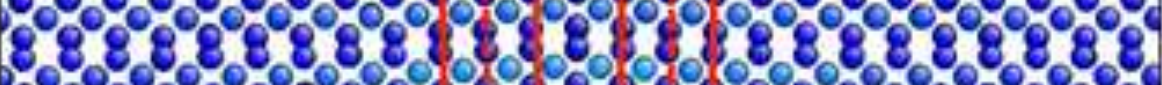

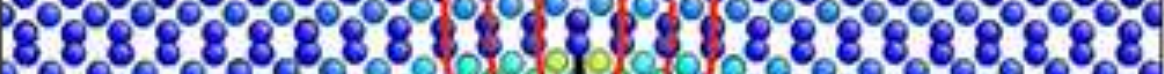

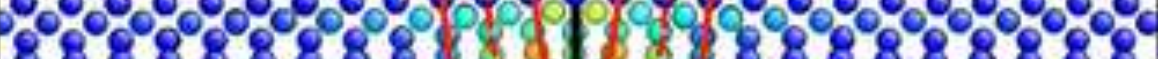
(1) $00 \%$ - $0010 \% 0 \%$ $8888.88 .80 .8 \% 8.8 \%$ $[010]-8 \% . \% \%$ $188 \% 8 \% 8 \%$ \% $8 \%$ \% $8 \%$ $18 \% 8 \% 8 \% \%$ 8. $001 \% 8 \% \%$

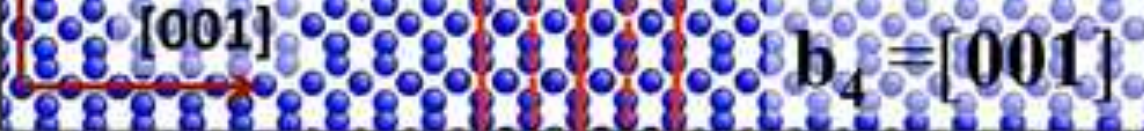

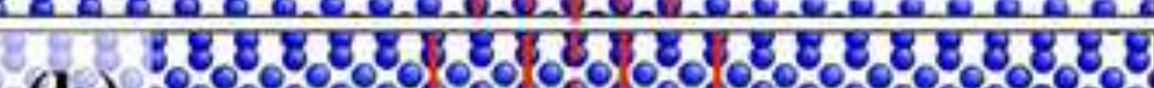

(b) $888888 \% 88888888$ $888.88 \% 8 \% 8 \% 8 \% 8 \%$

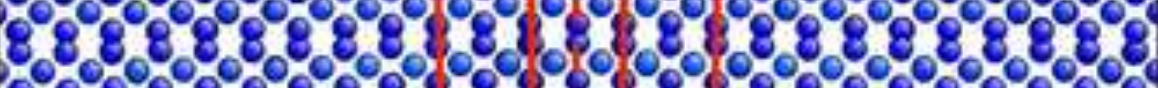
$88888888 \% 8 \% 8 \% 88 \%$ $88888888 \% 8 \% 8 \% 8 \% 8 \%$ $88888888 \% 8 \% 888888 \%$ 8888888814018888888 $8888.8 \% 8 \%$ $[010]-8 \% \% 0 \%$ $0 \% \% 0 \% 0 \% 0 \%$ $8.8 .8 \% 8 \% .8 \% 8.8 \%$ $88.88 .8 \% 8 \% .8 \% 8 \% 8 \%$

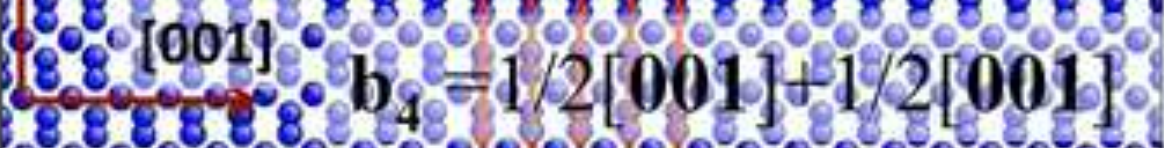

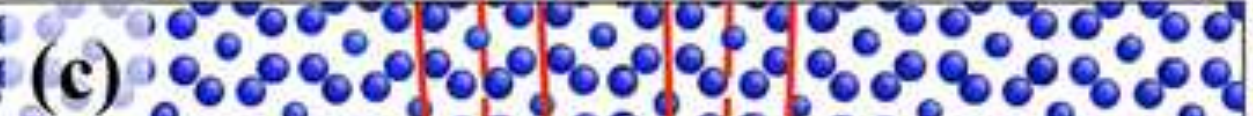

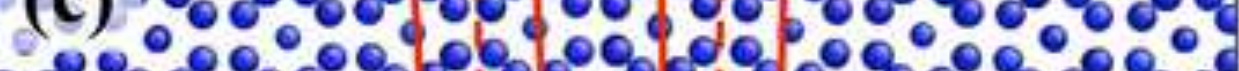
$00^{\circ} 00^{\circ}$

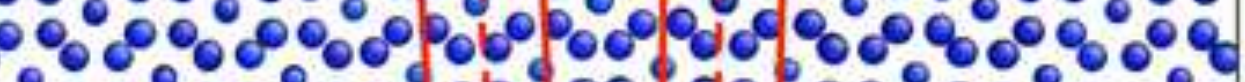

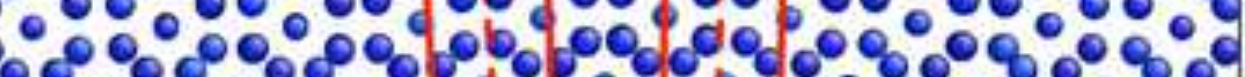
(

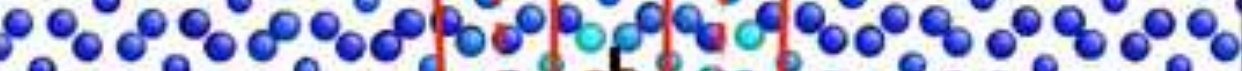

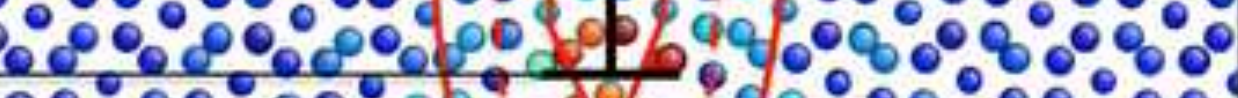

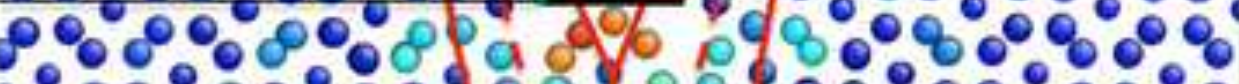

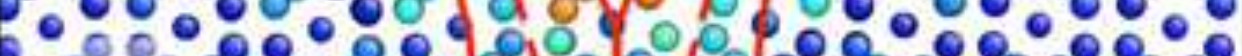
$101010^{\circ} 0_{0}^{\circ} 0_{0}^{\circ} 0_{0}^{\circ} 0_{0}^{\circ} 0^{\circ} 0^{\circ}$

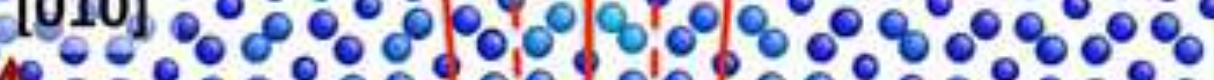

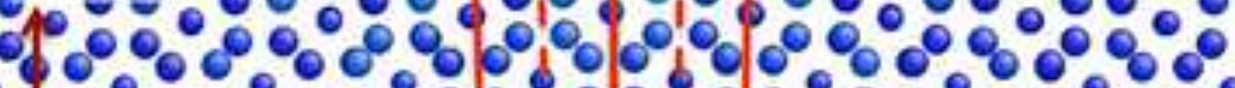
$10^{\circ} 00^{\circ} 00^{\circ} 00^{\circ} 0^{\circ} 00^{\circ} 0^{\circ} 0$

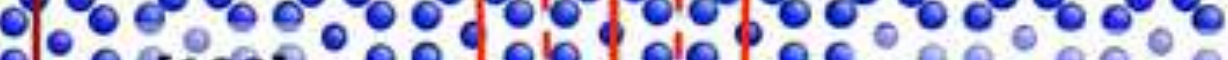

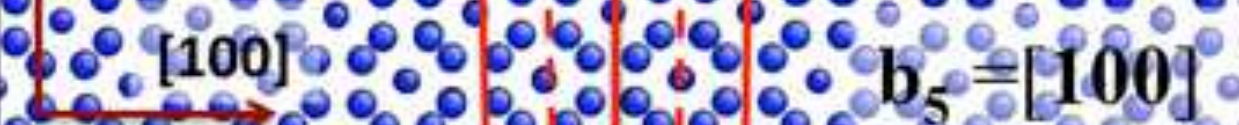

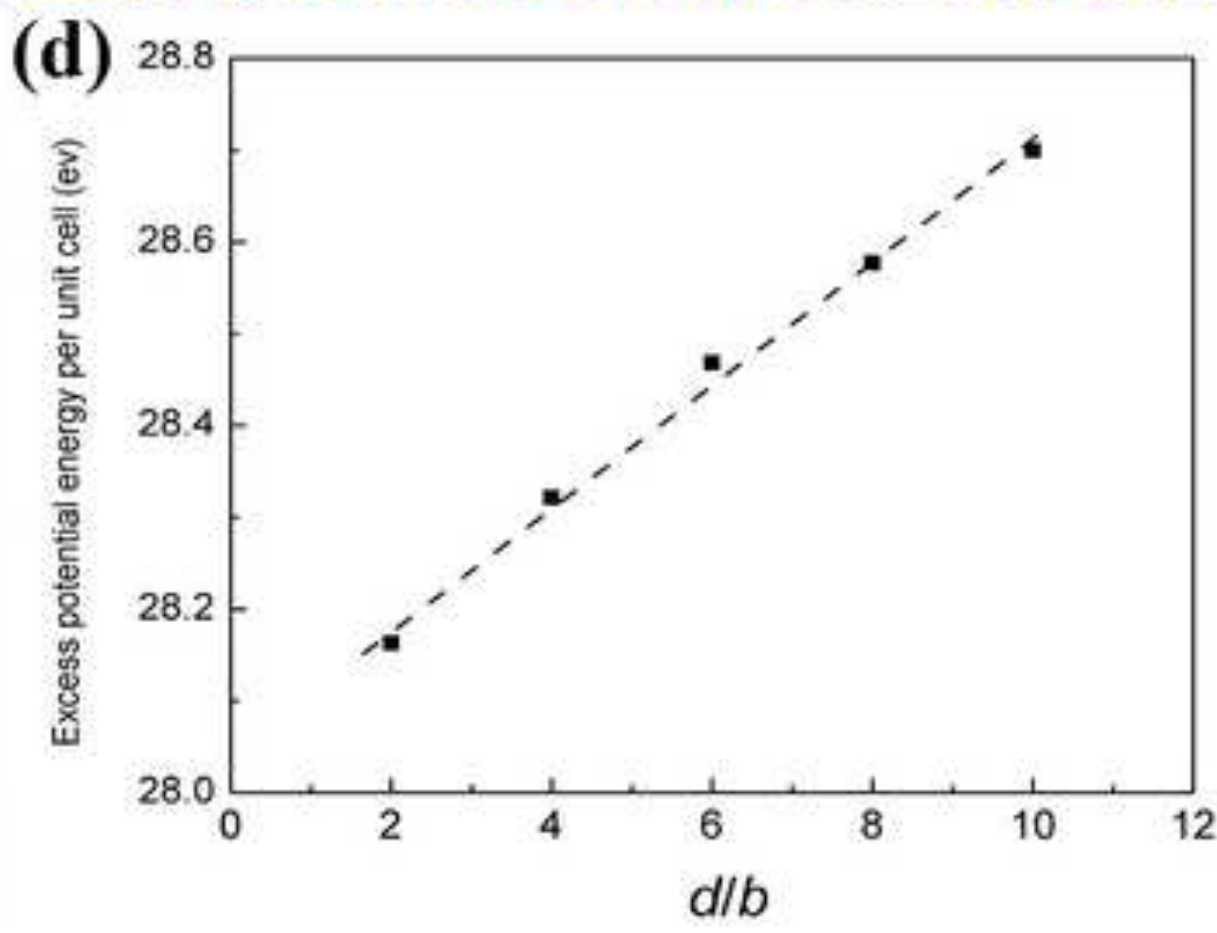



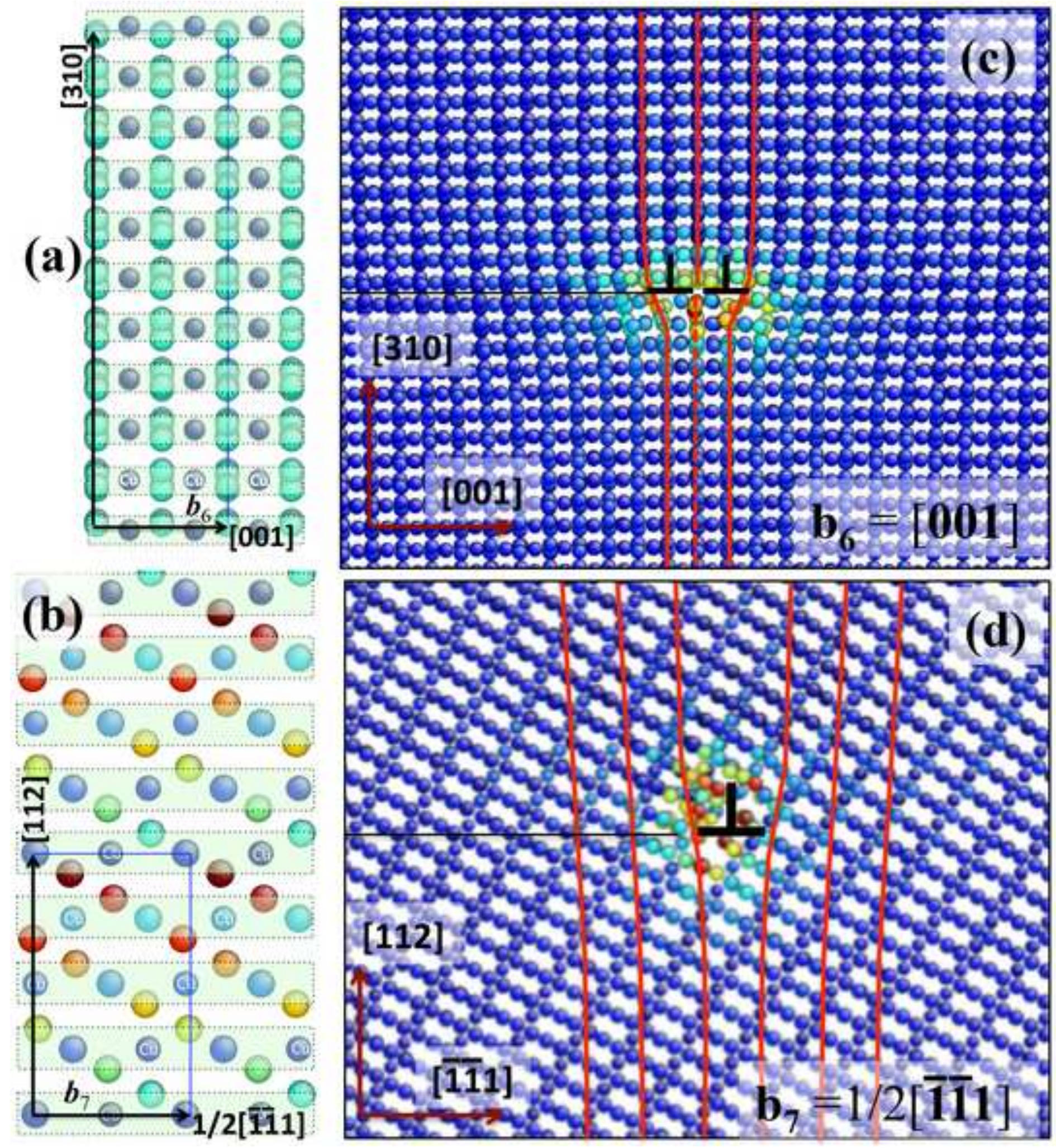


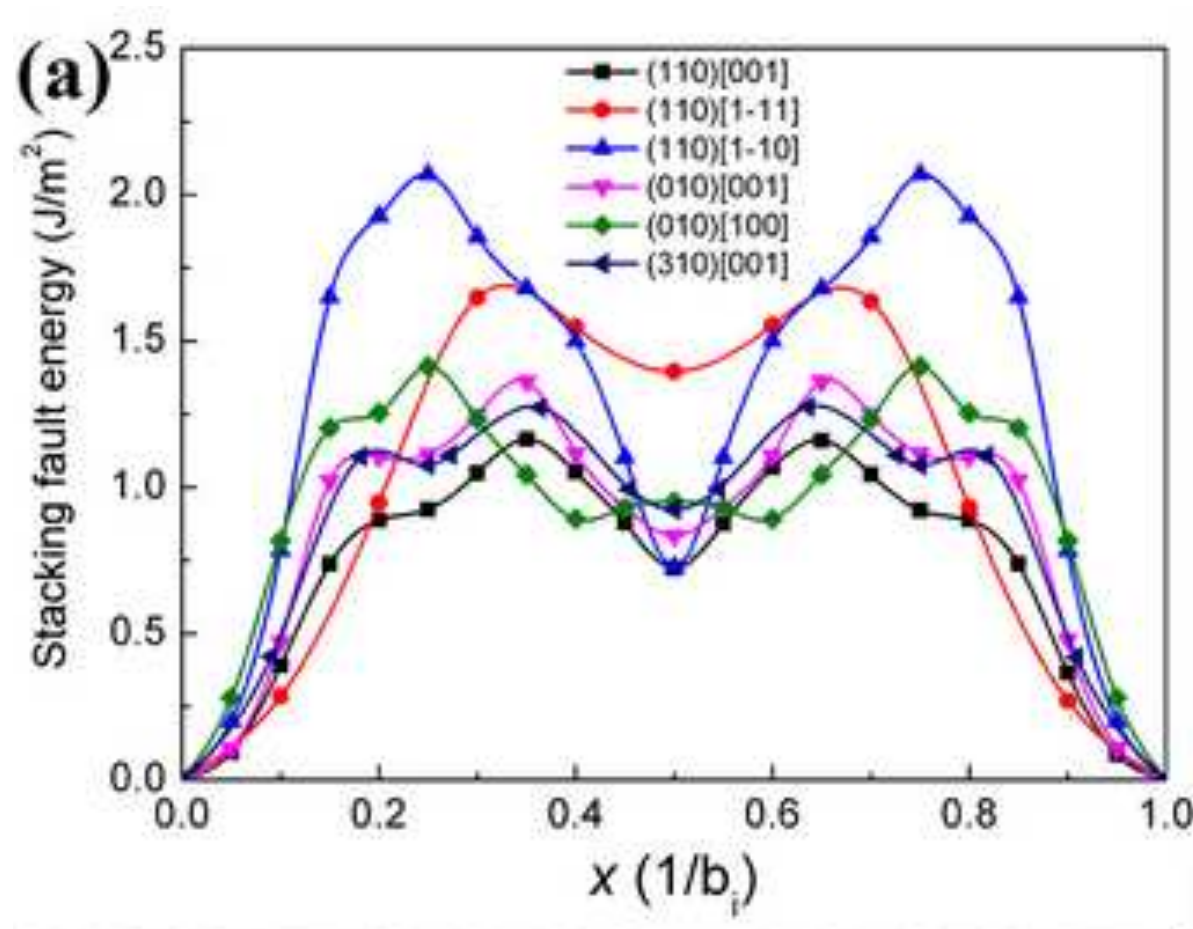

(c) 88.888 .888 .88888

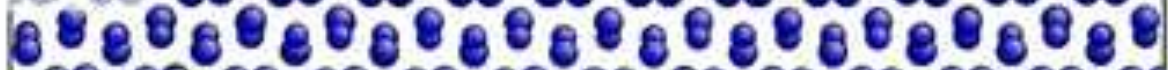

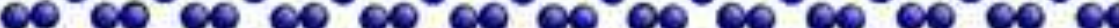

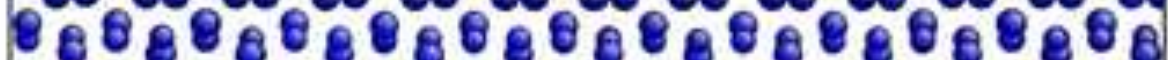
70000000000000000

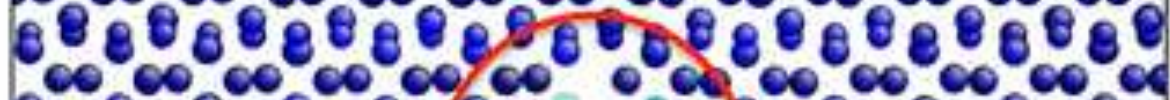

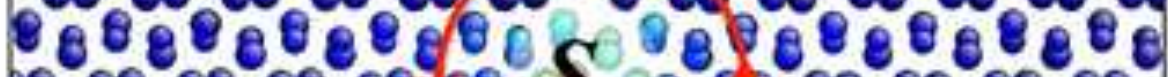

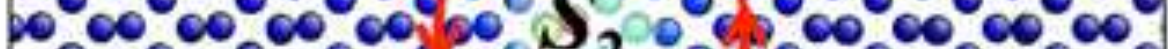

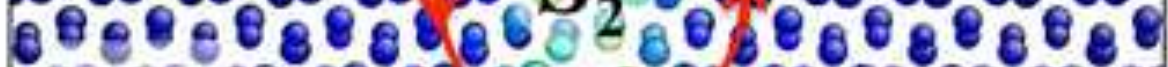
- 1112100.0000000 $10 \times 0010000 \times 00000000$

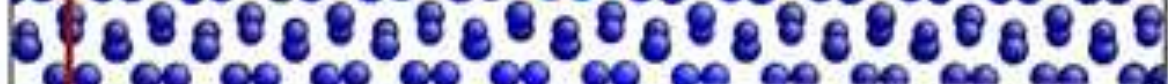
$00 \infty 00 \times \infty$

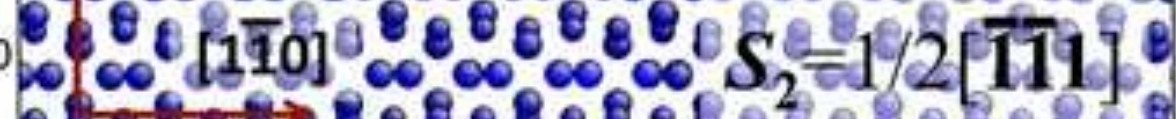

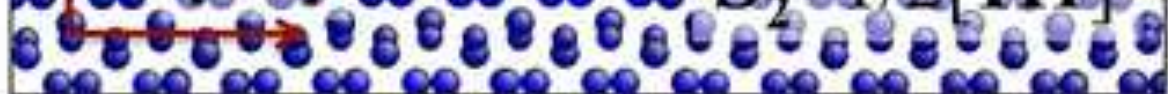

(b) 80808080808080

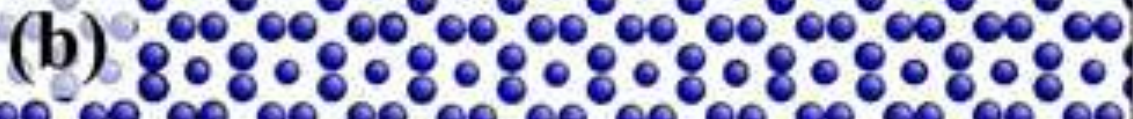

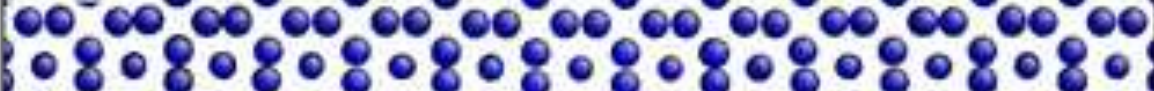
(d) $80808 \%$ (d) $80080 \% 80808 \%$

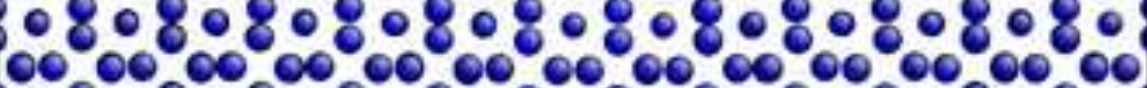

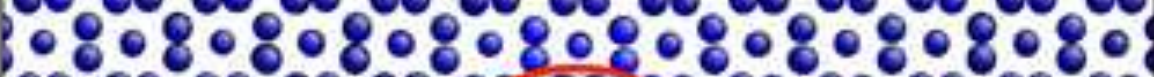
0000000000000

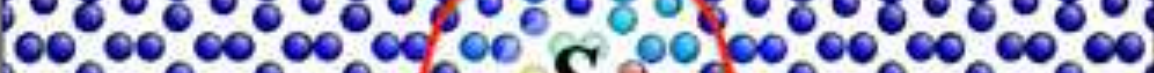

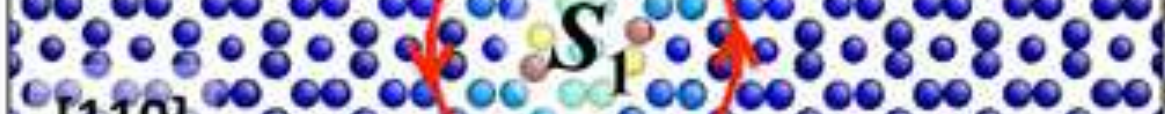

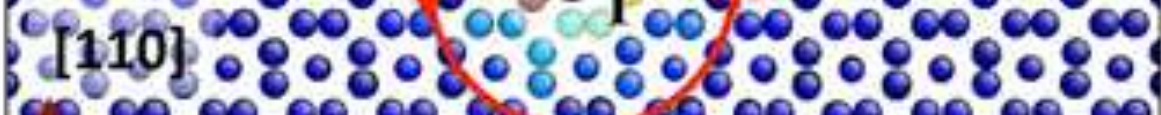

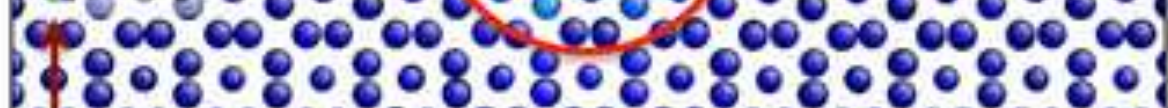

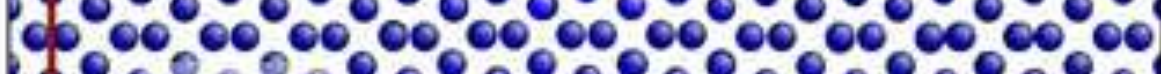

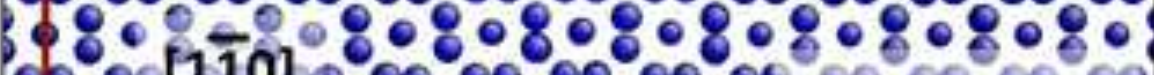
প.8

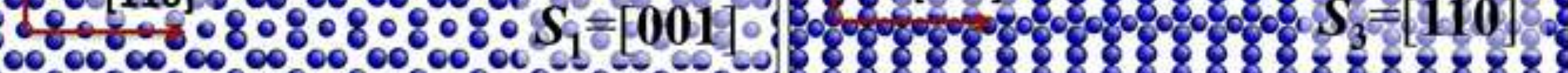

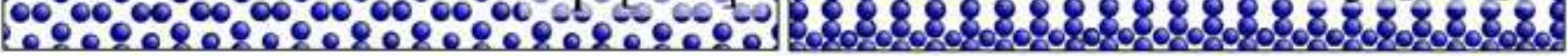




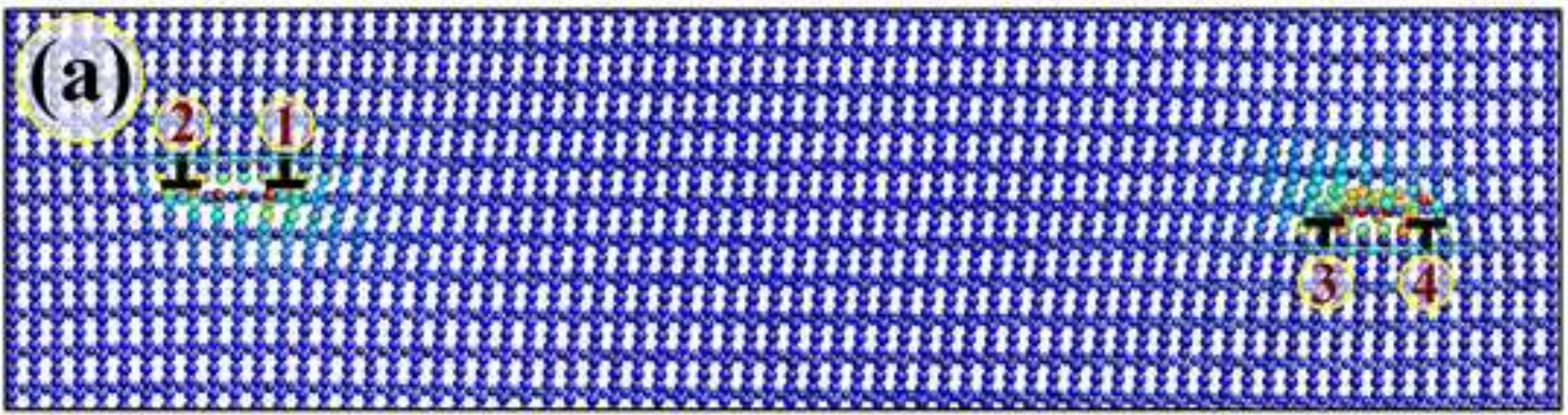

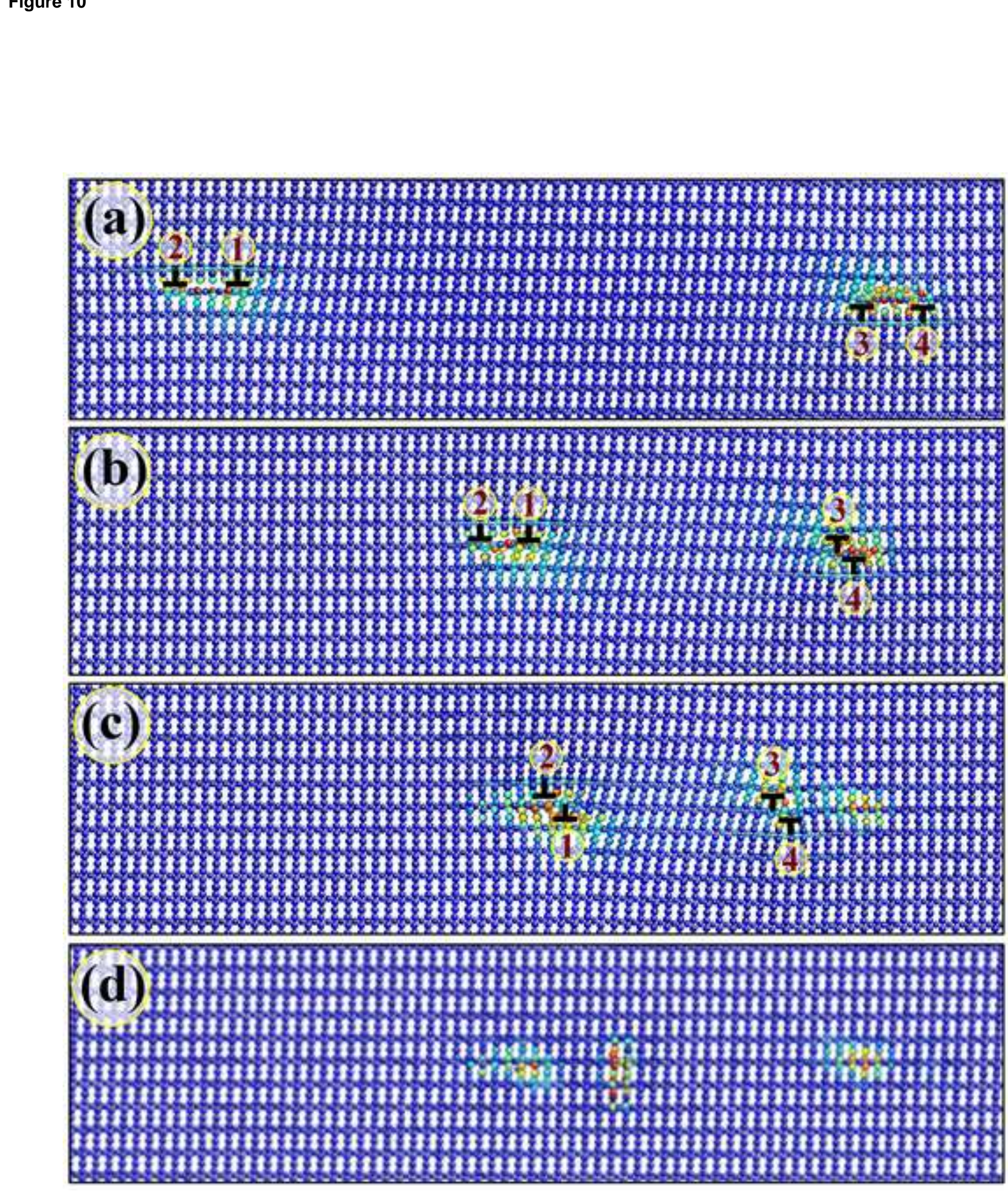

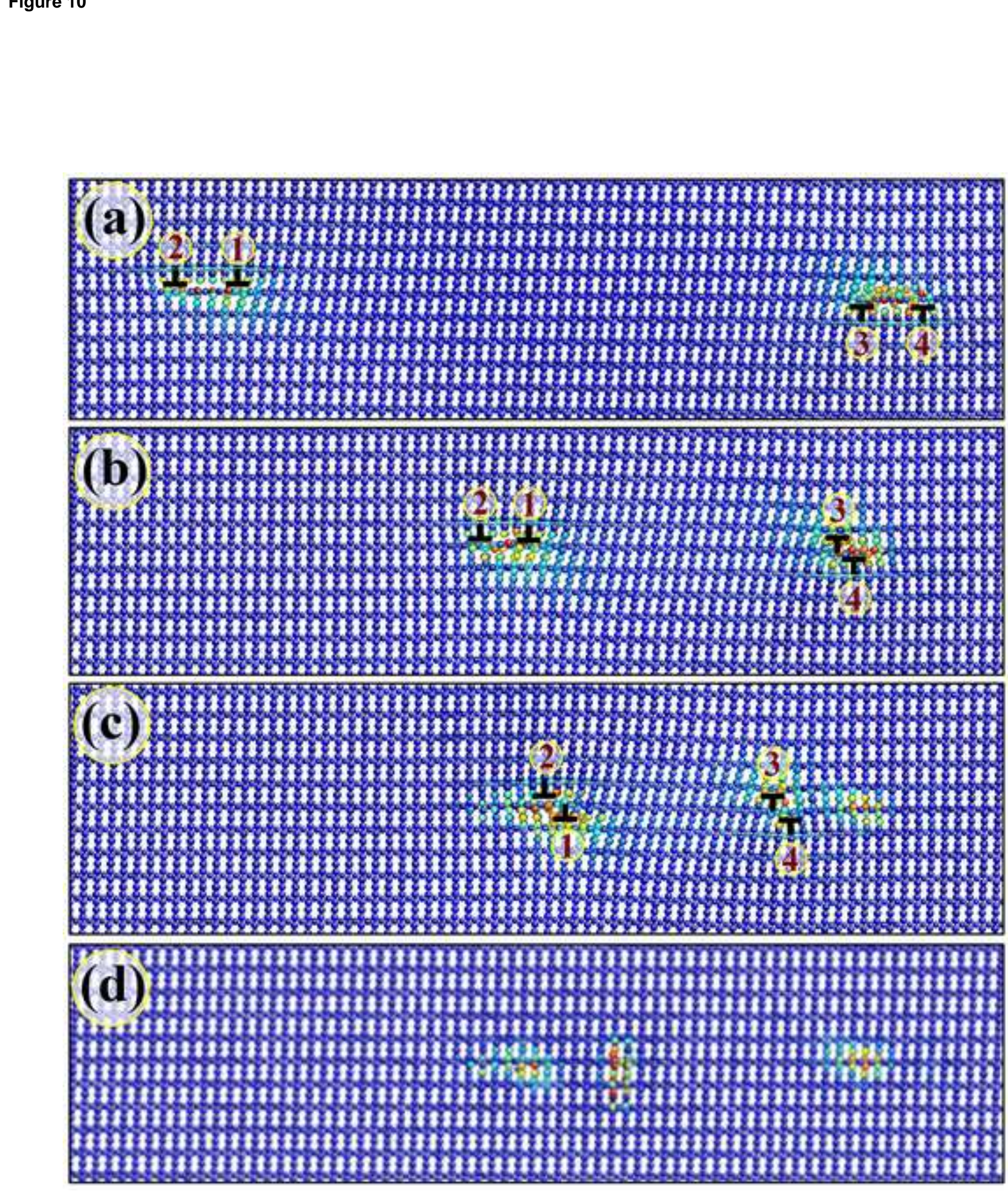

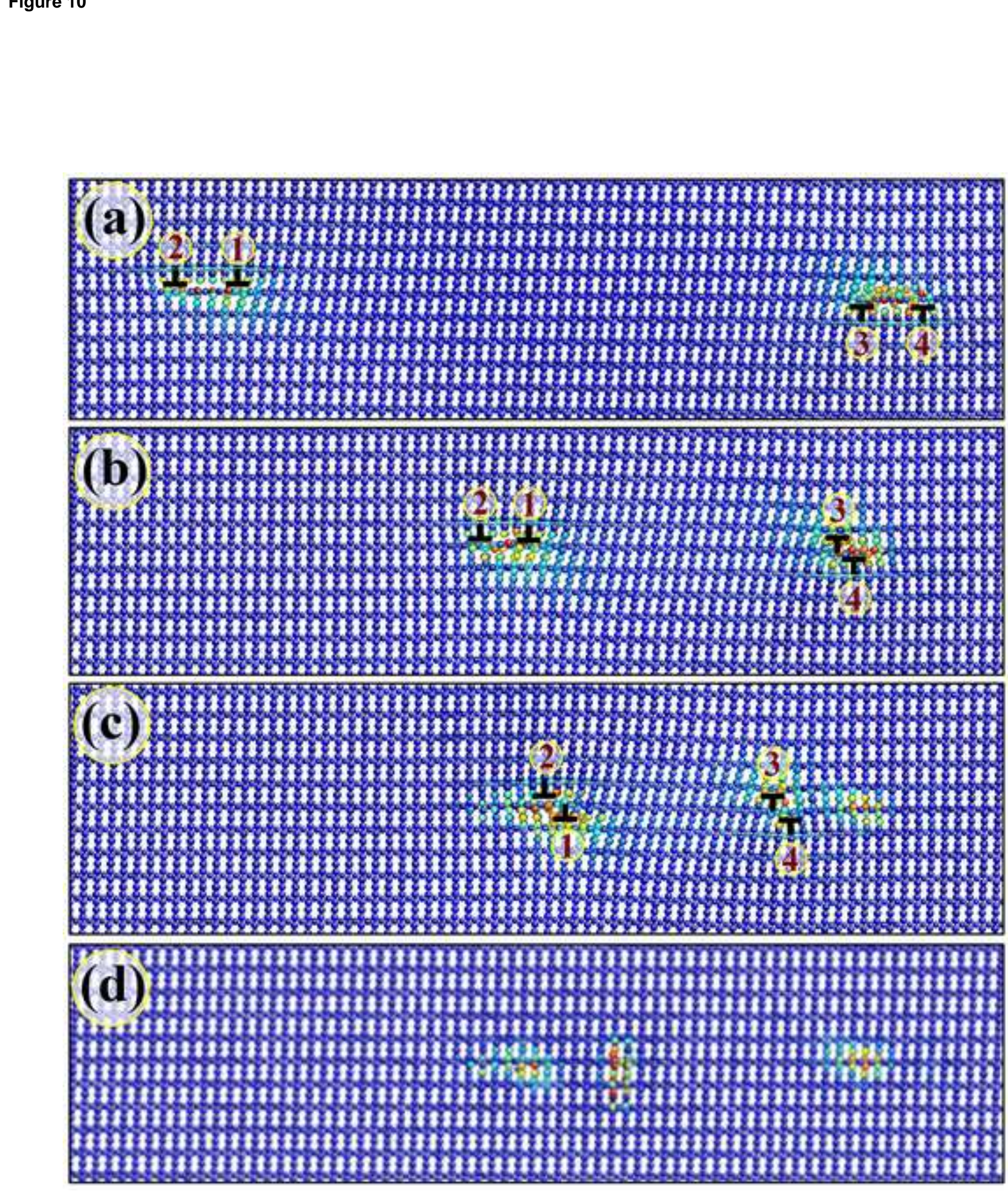

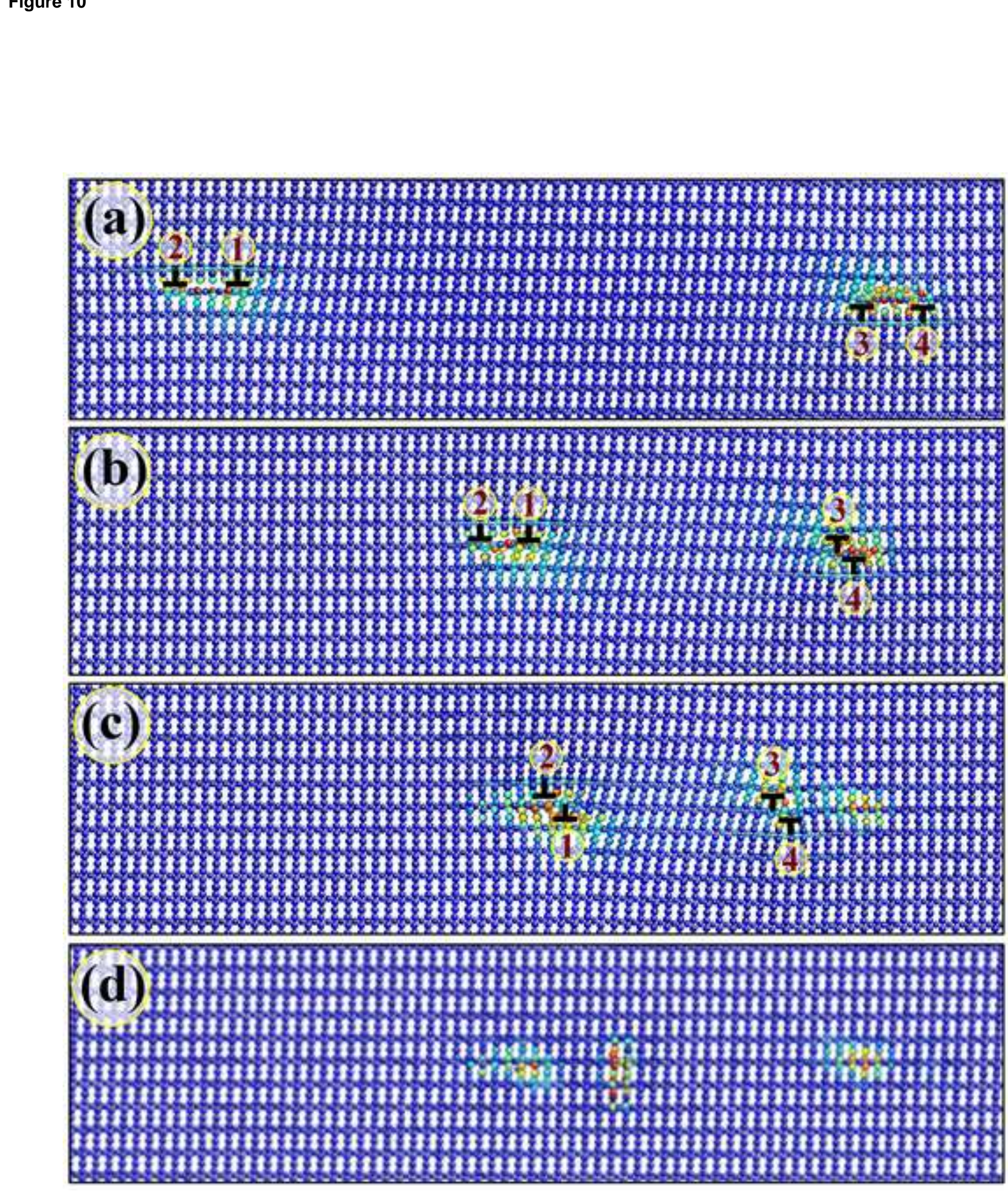

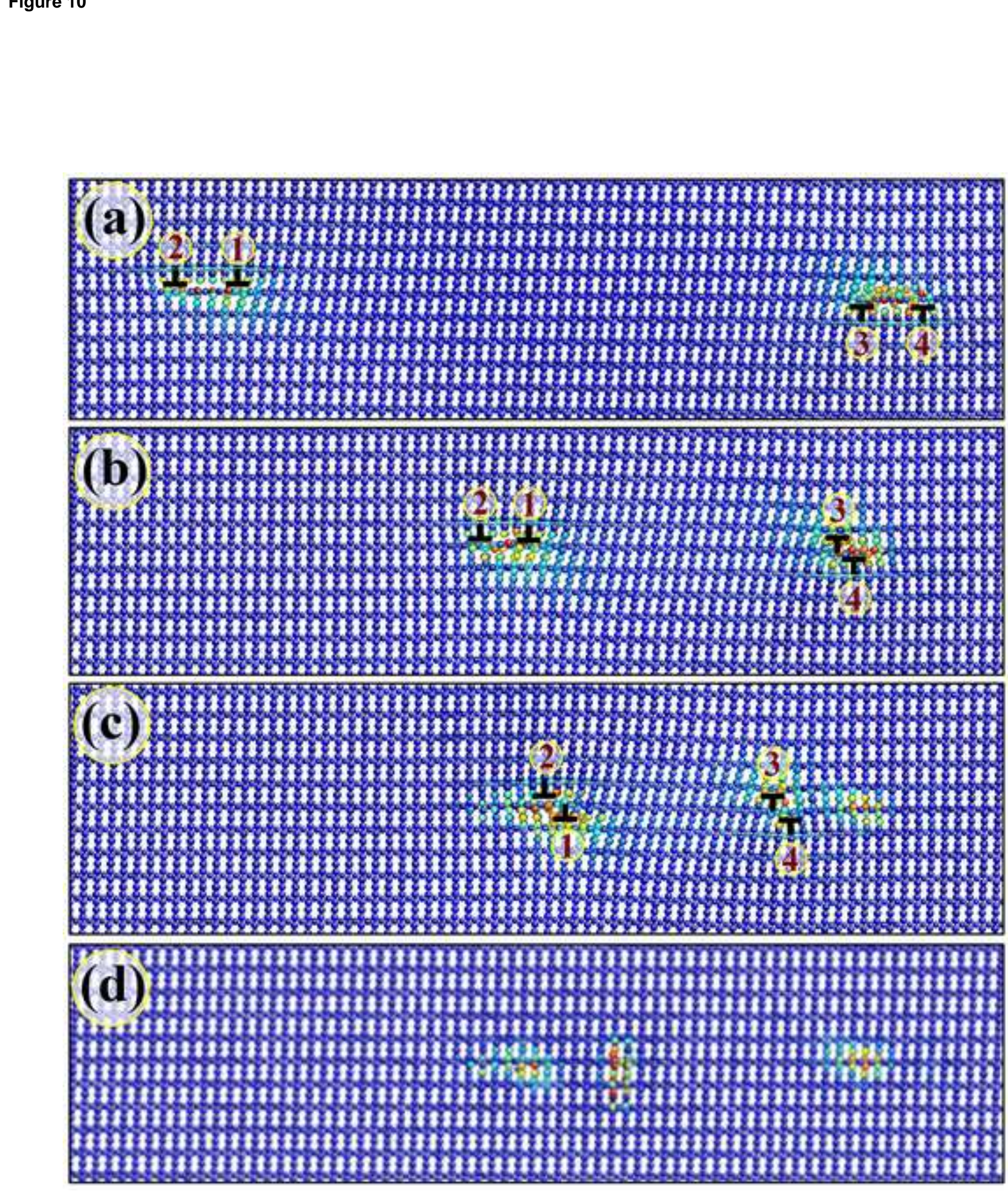

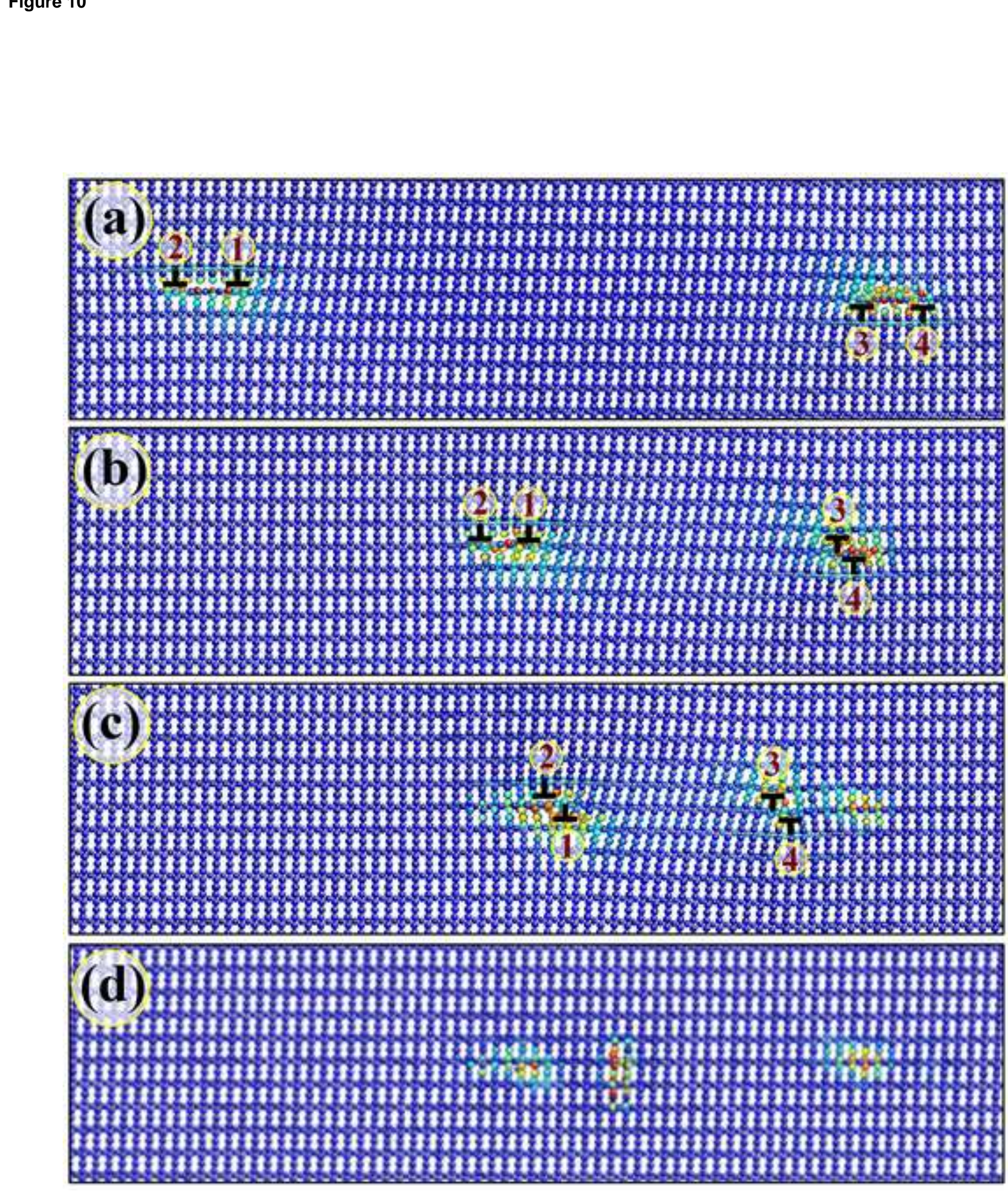

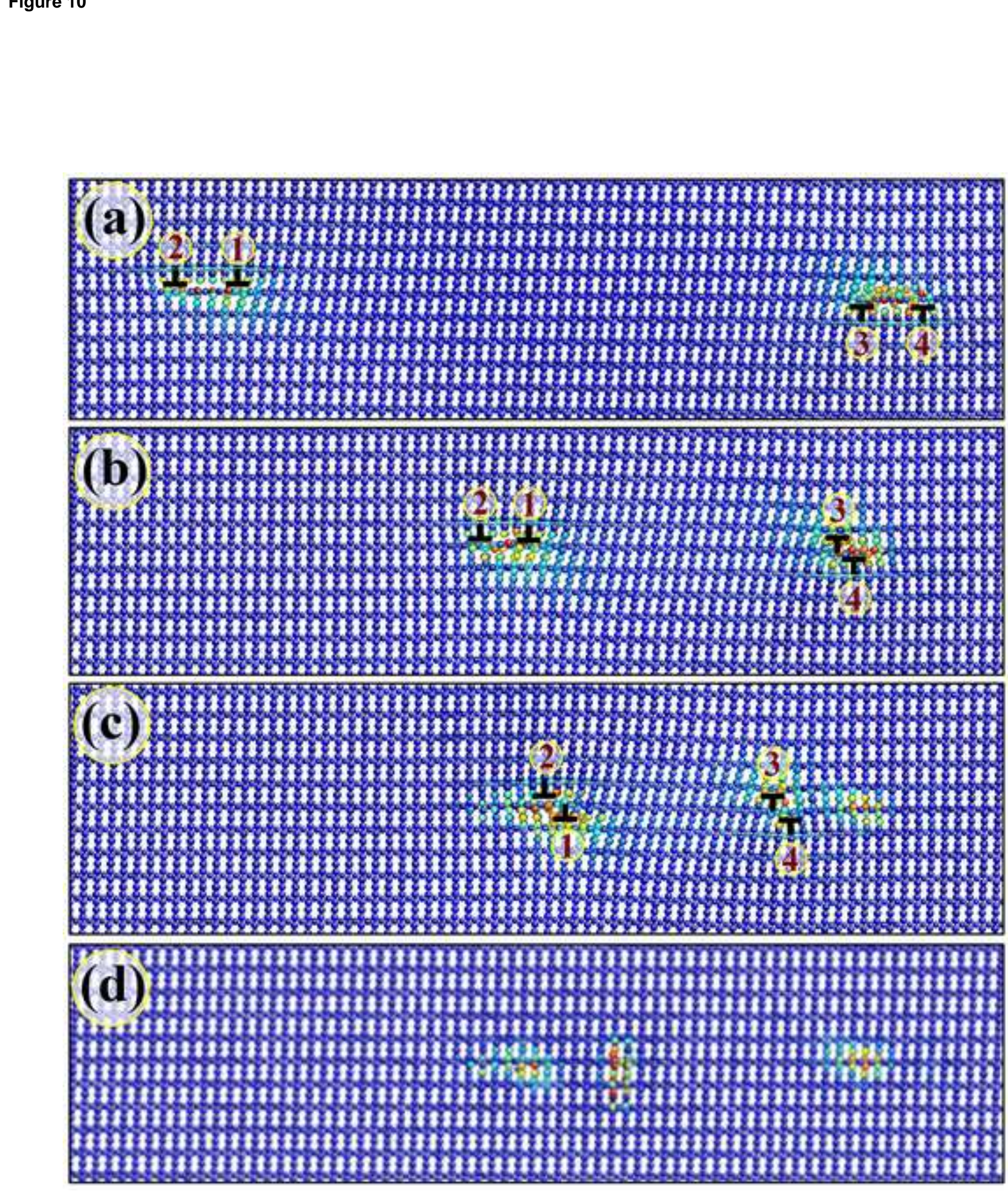

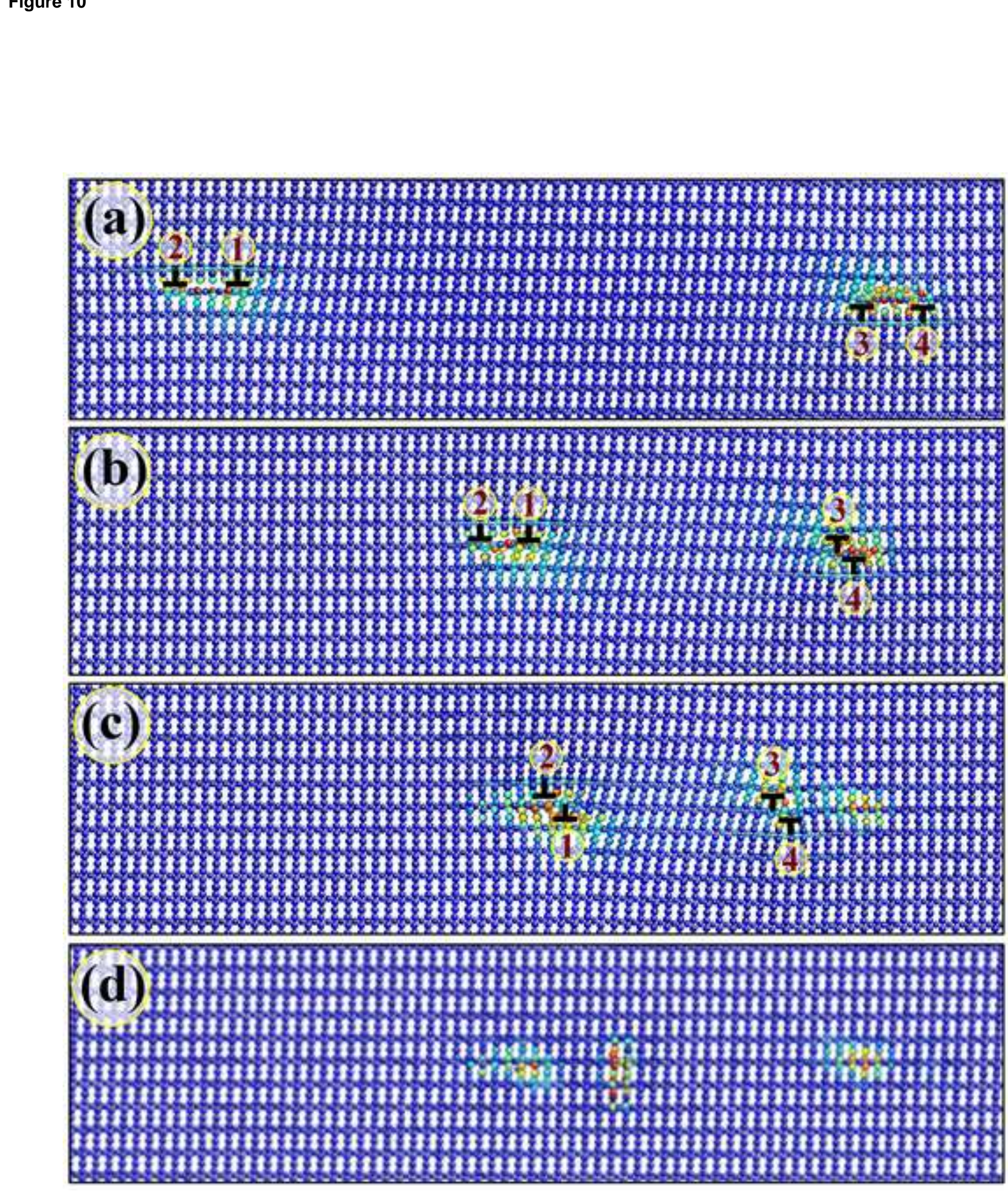

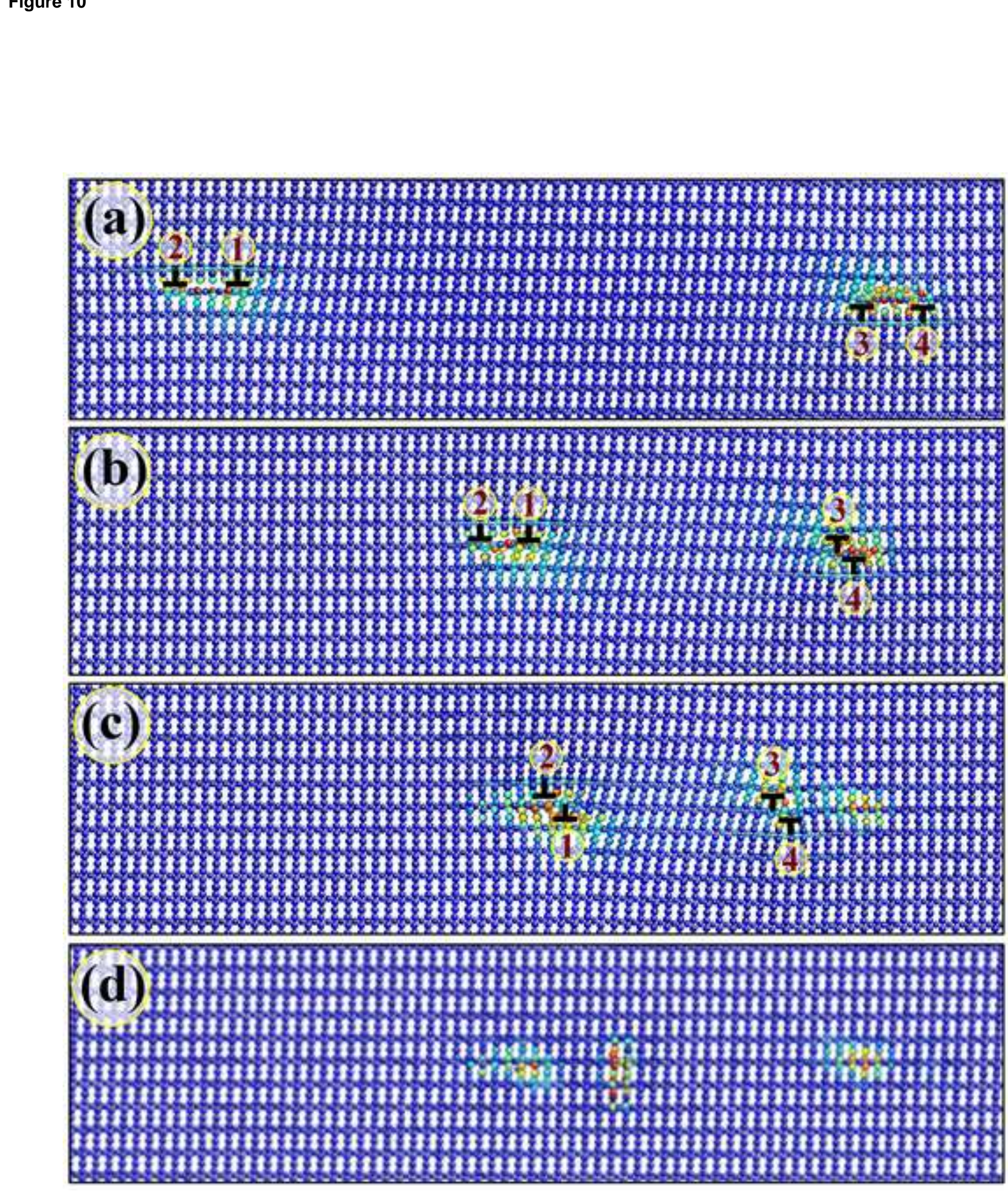

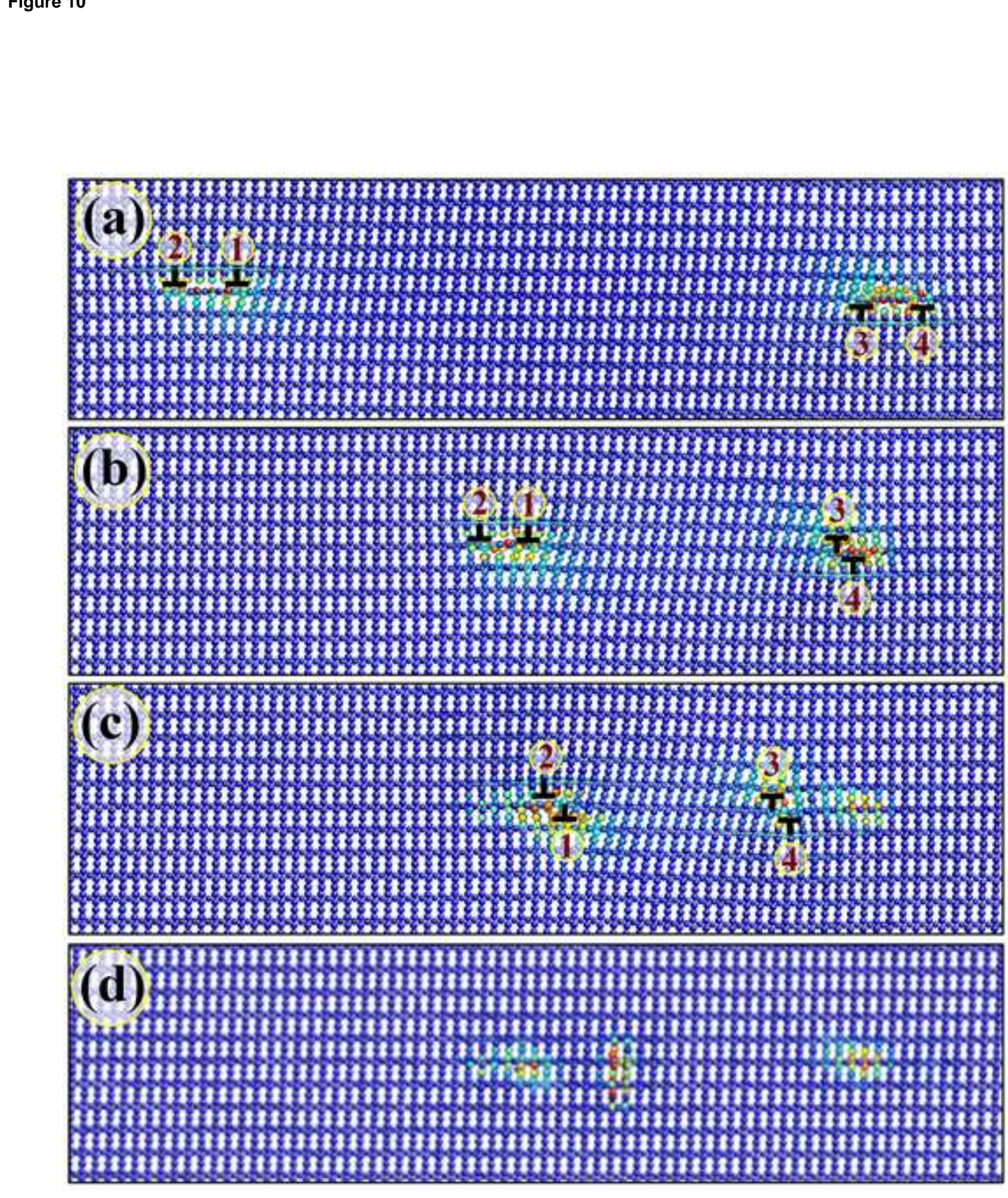

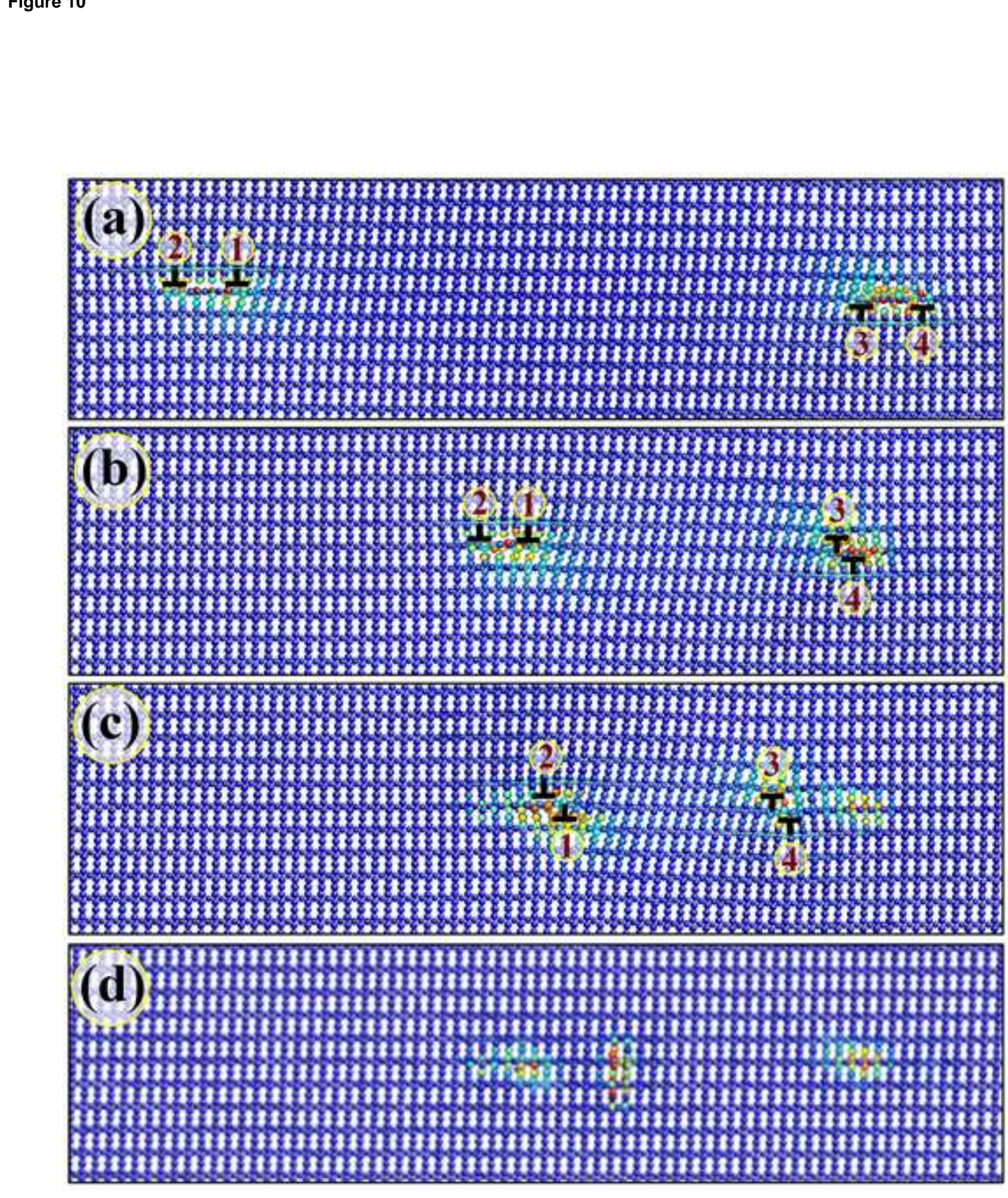

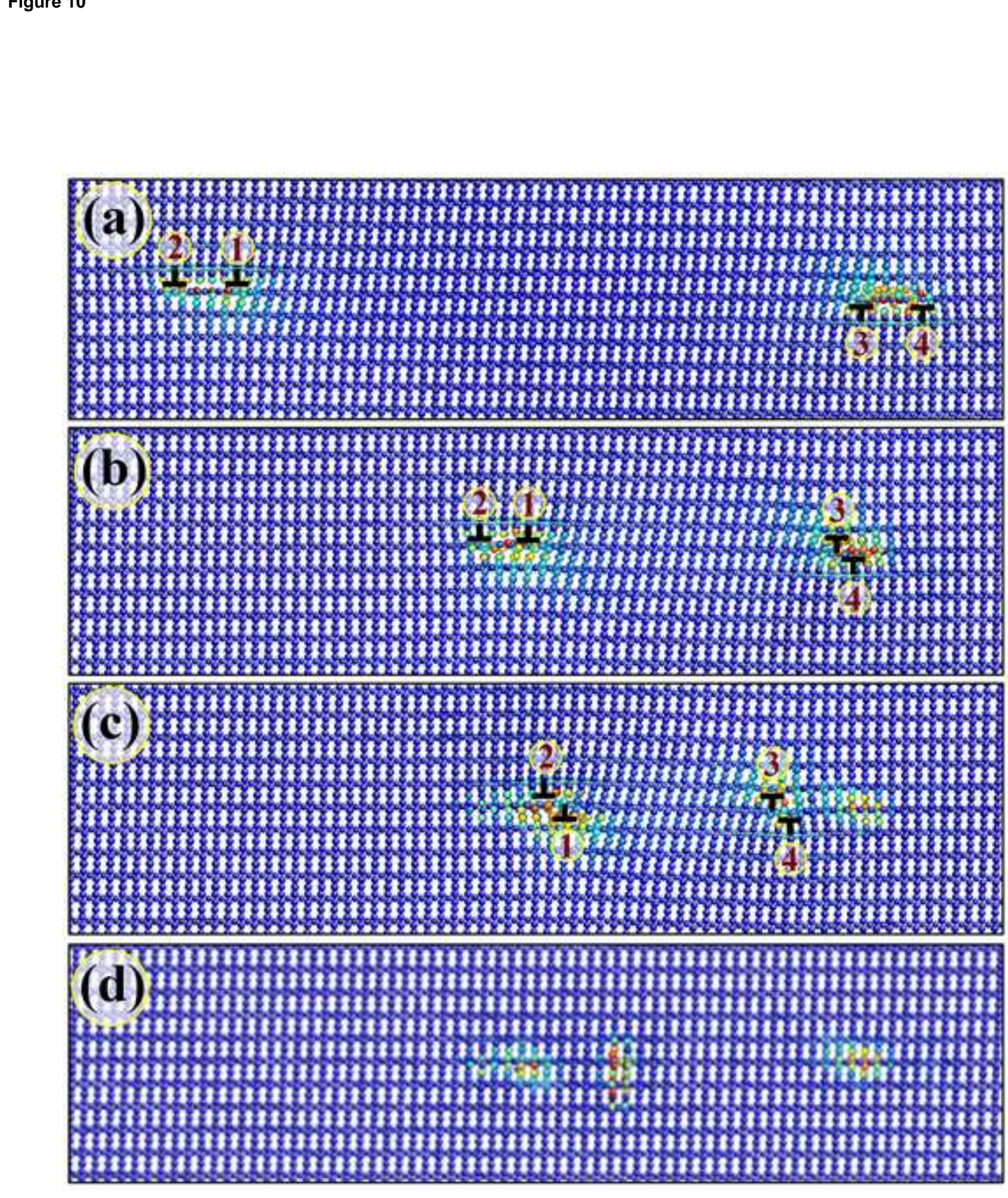

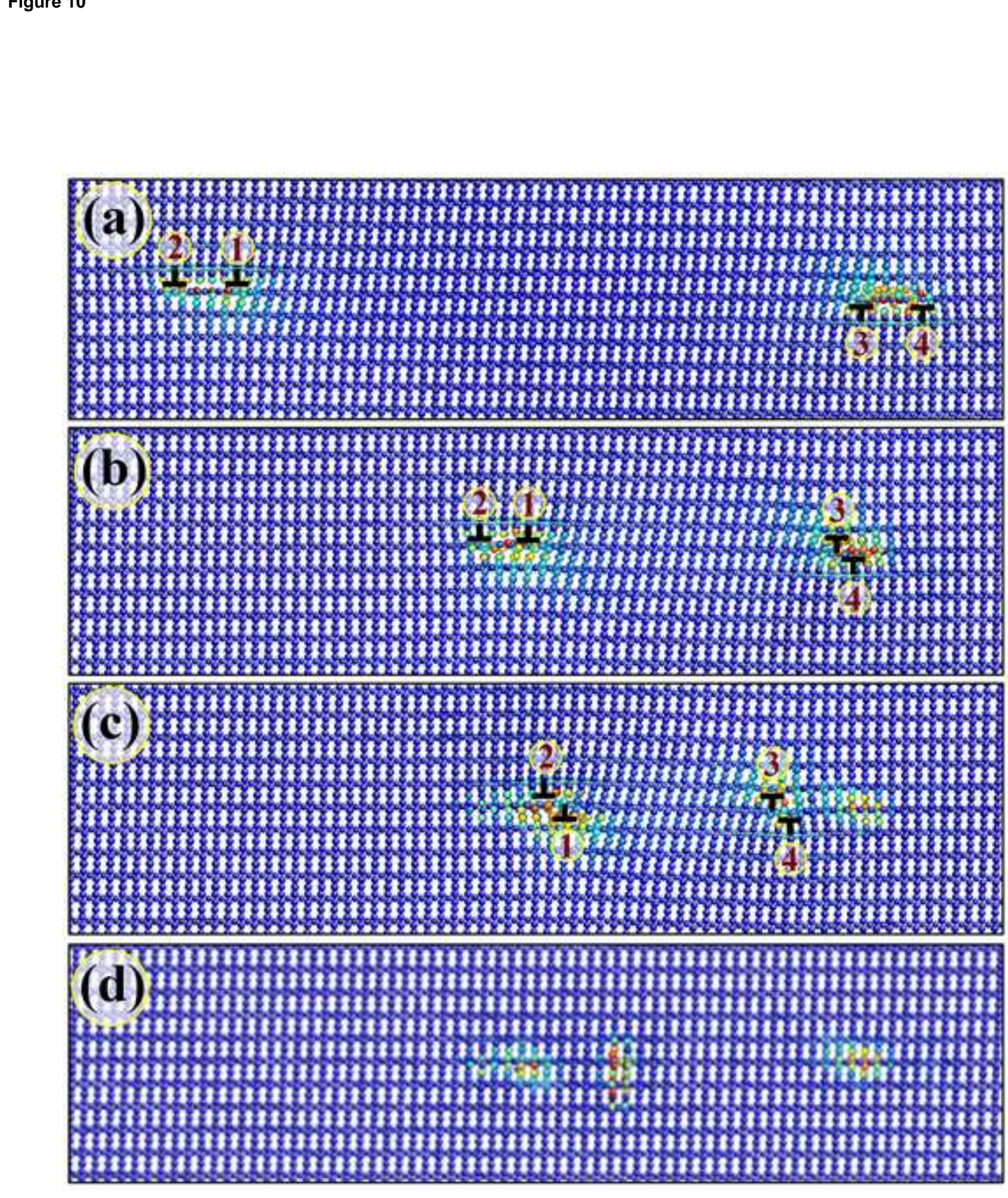

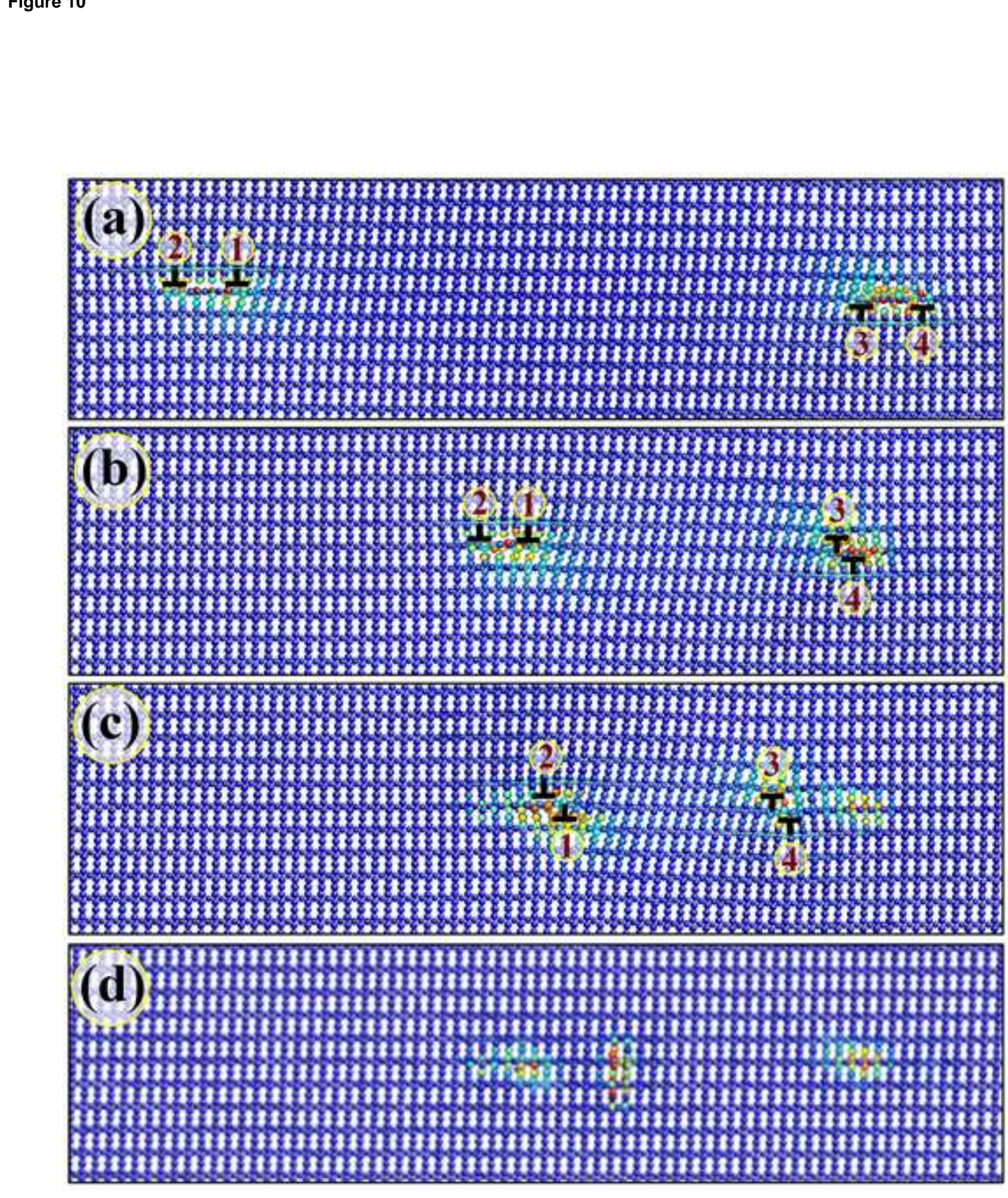

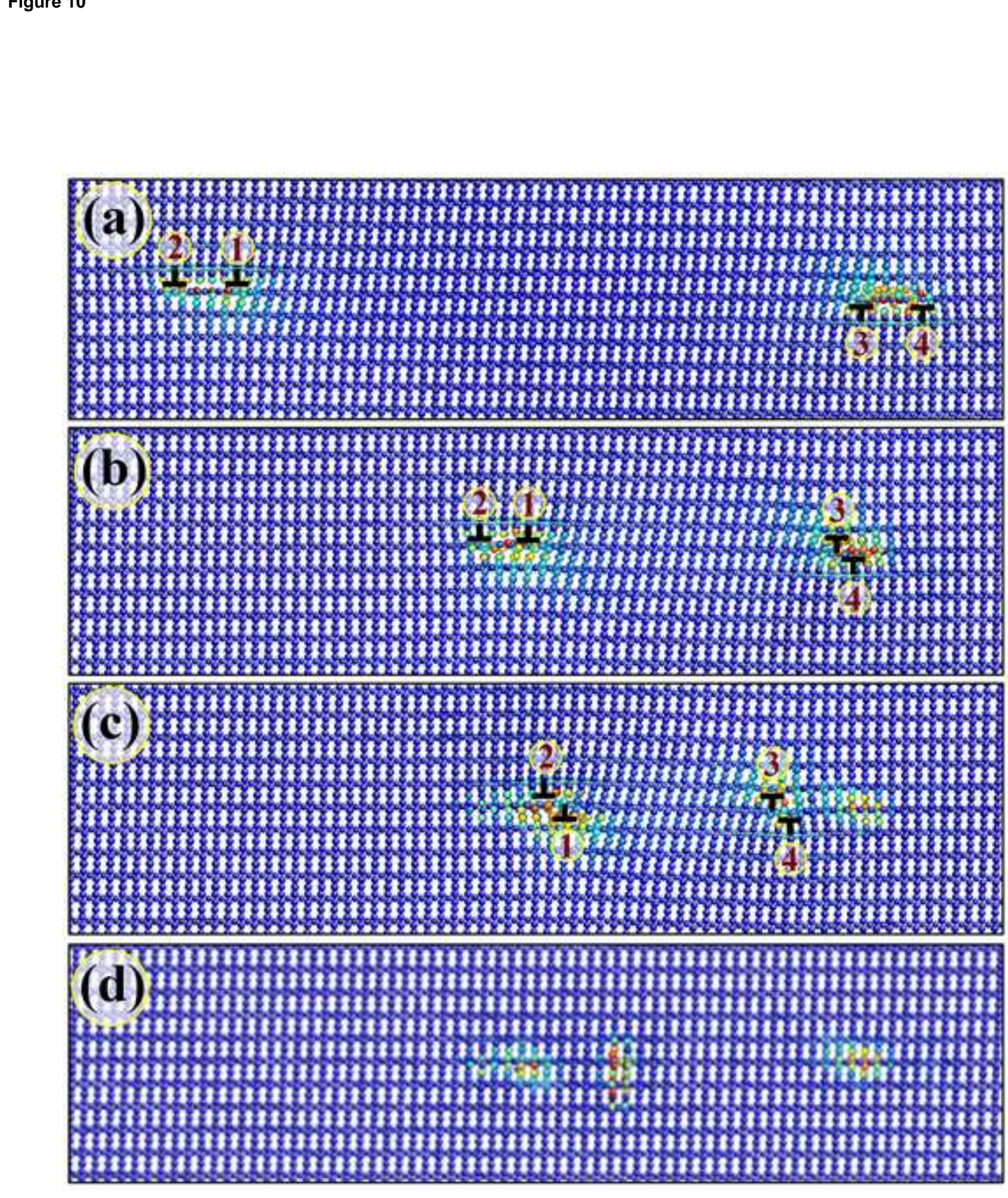

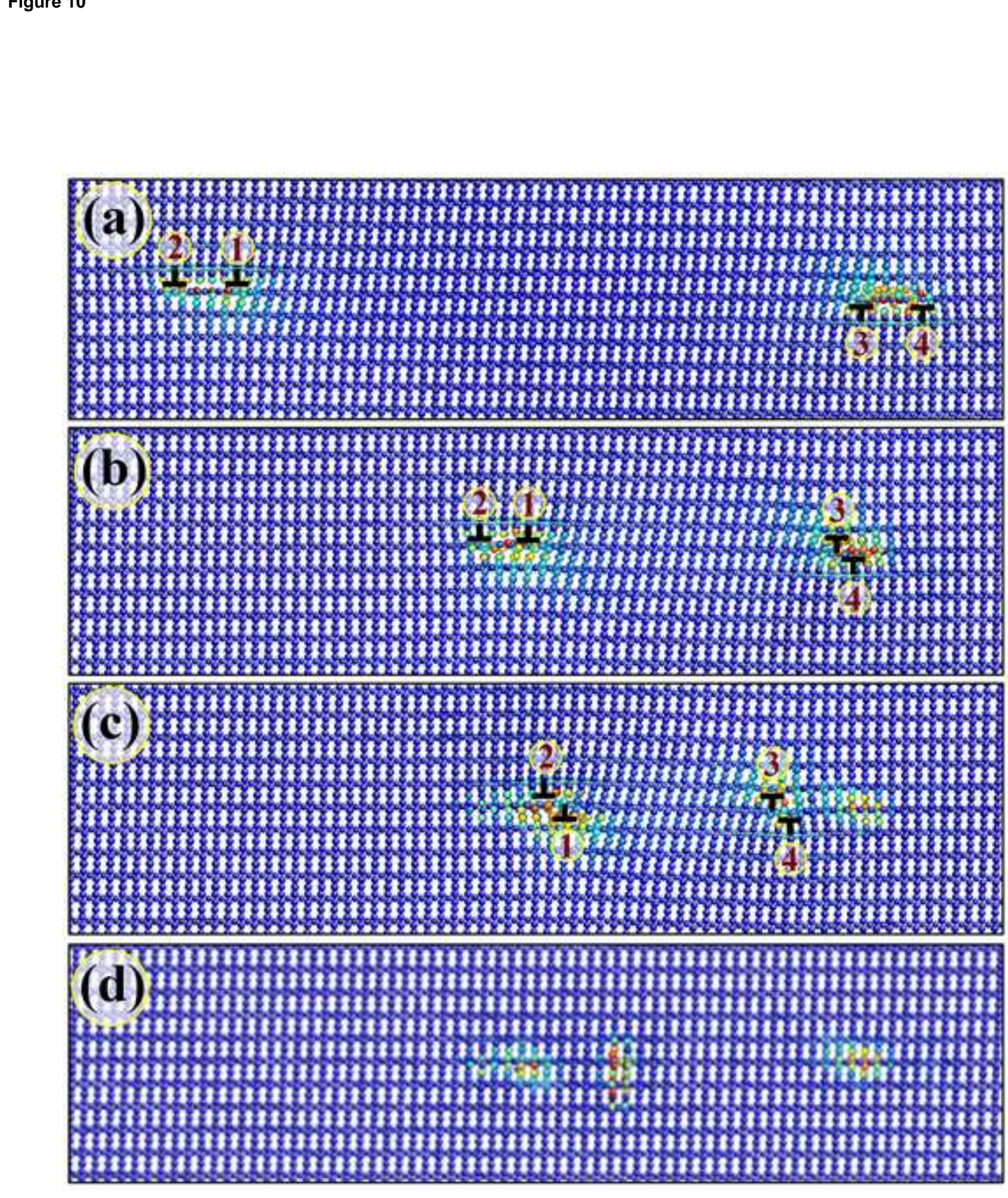

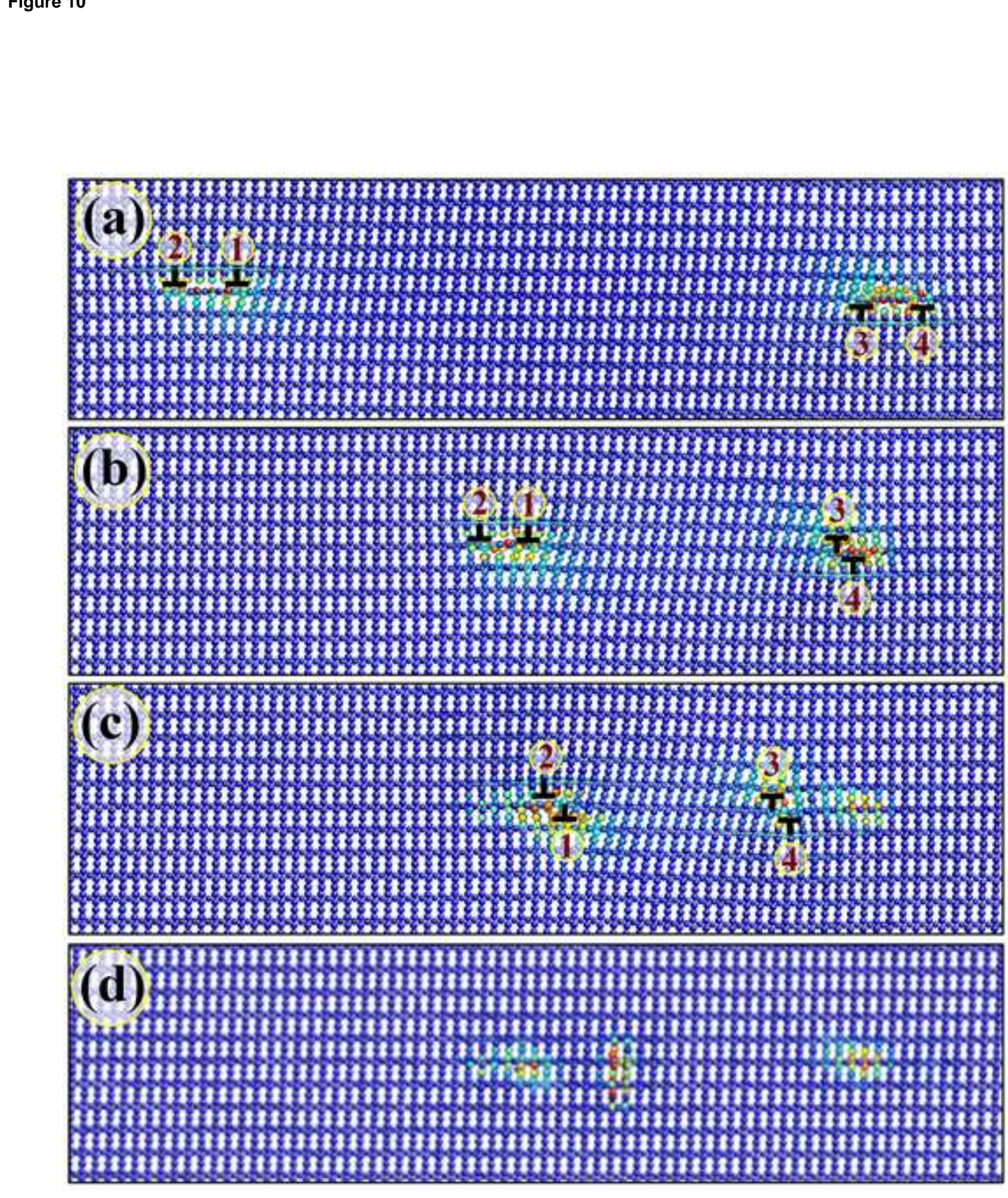

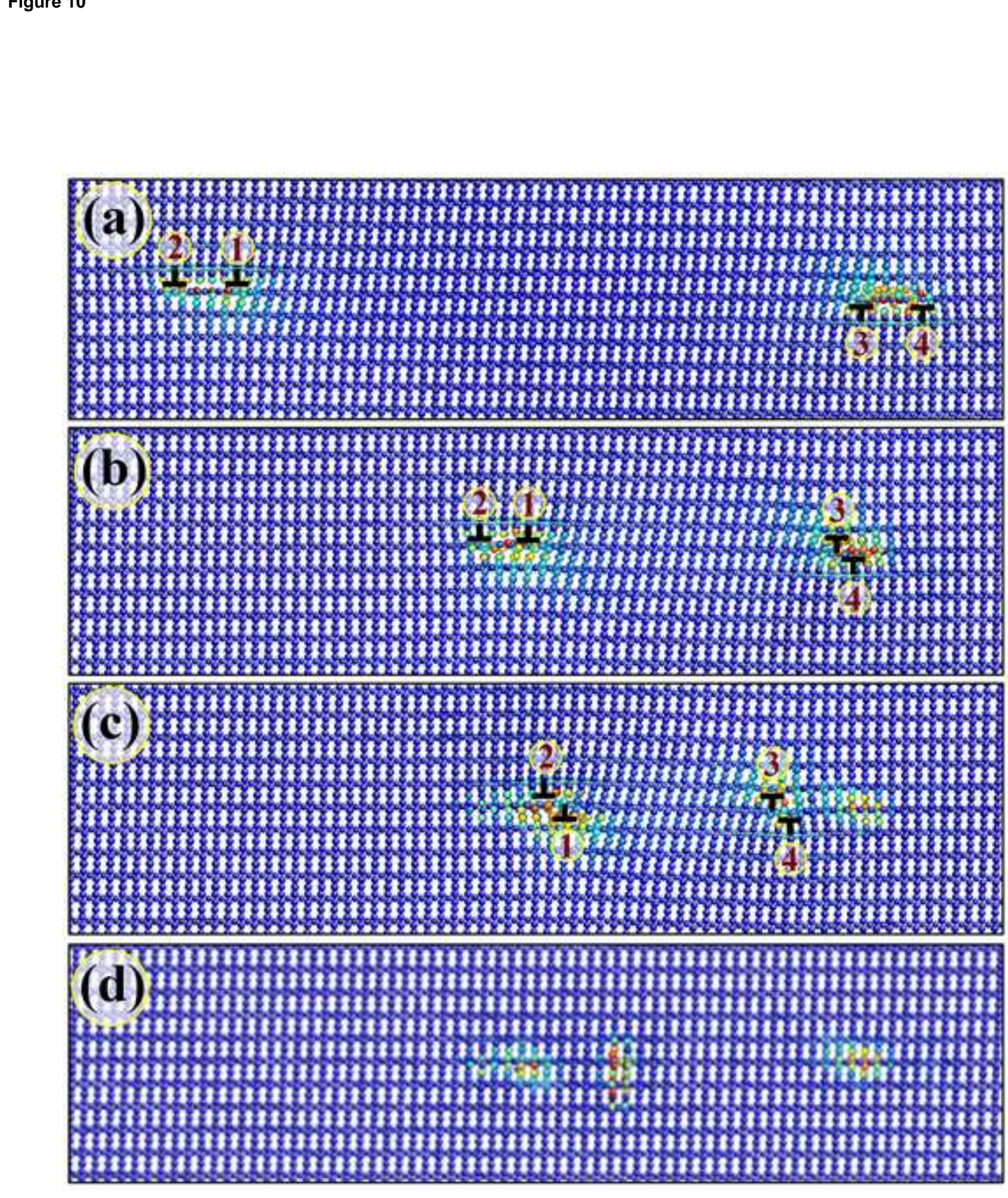

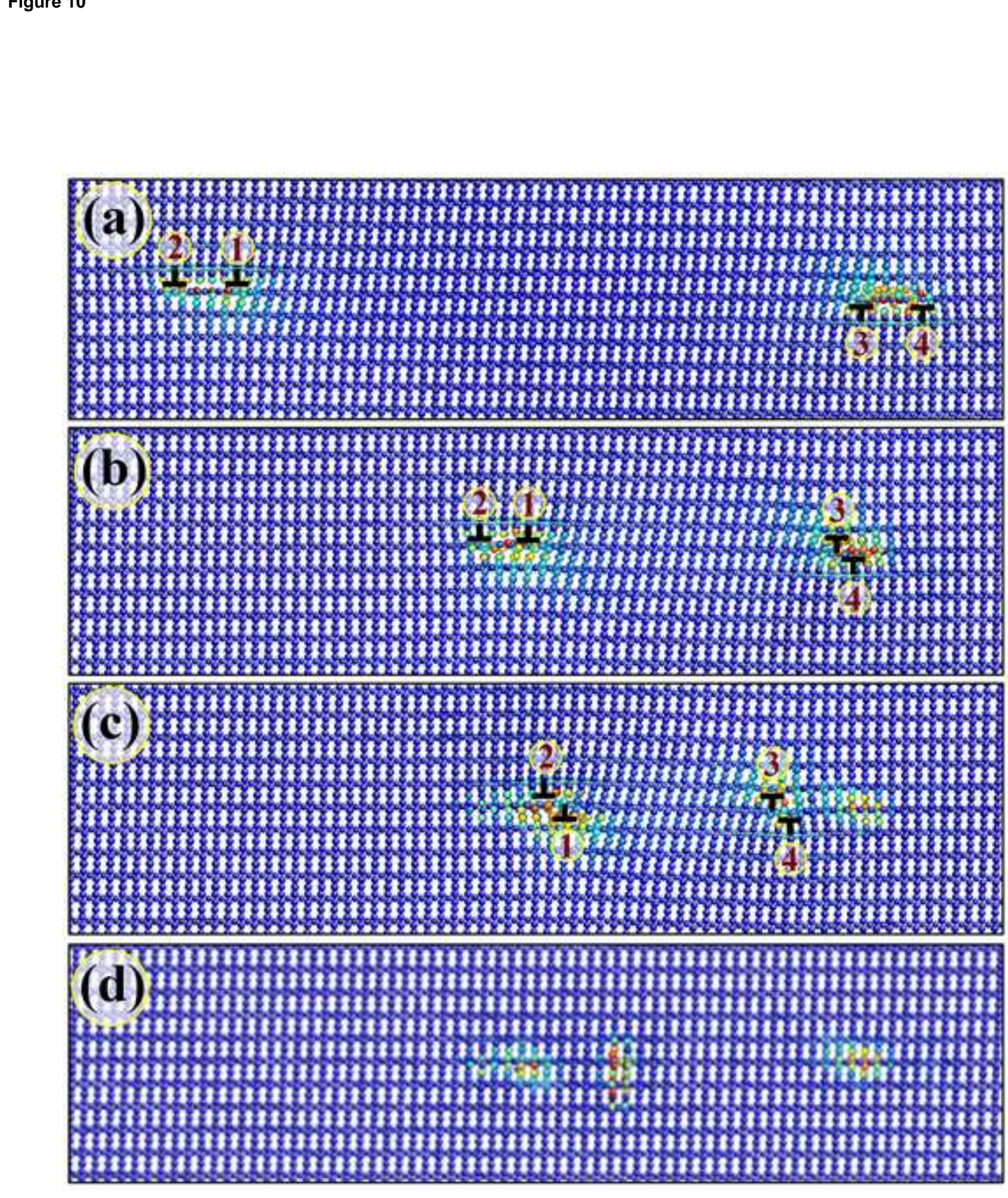
.

.

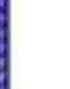

.



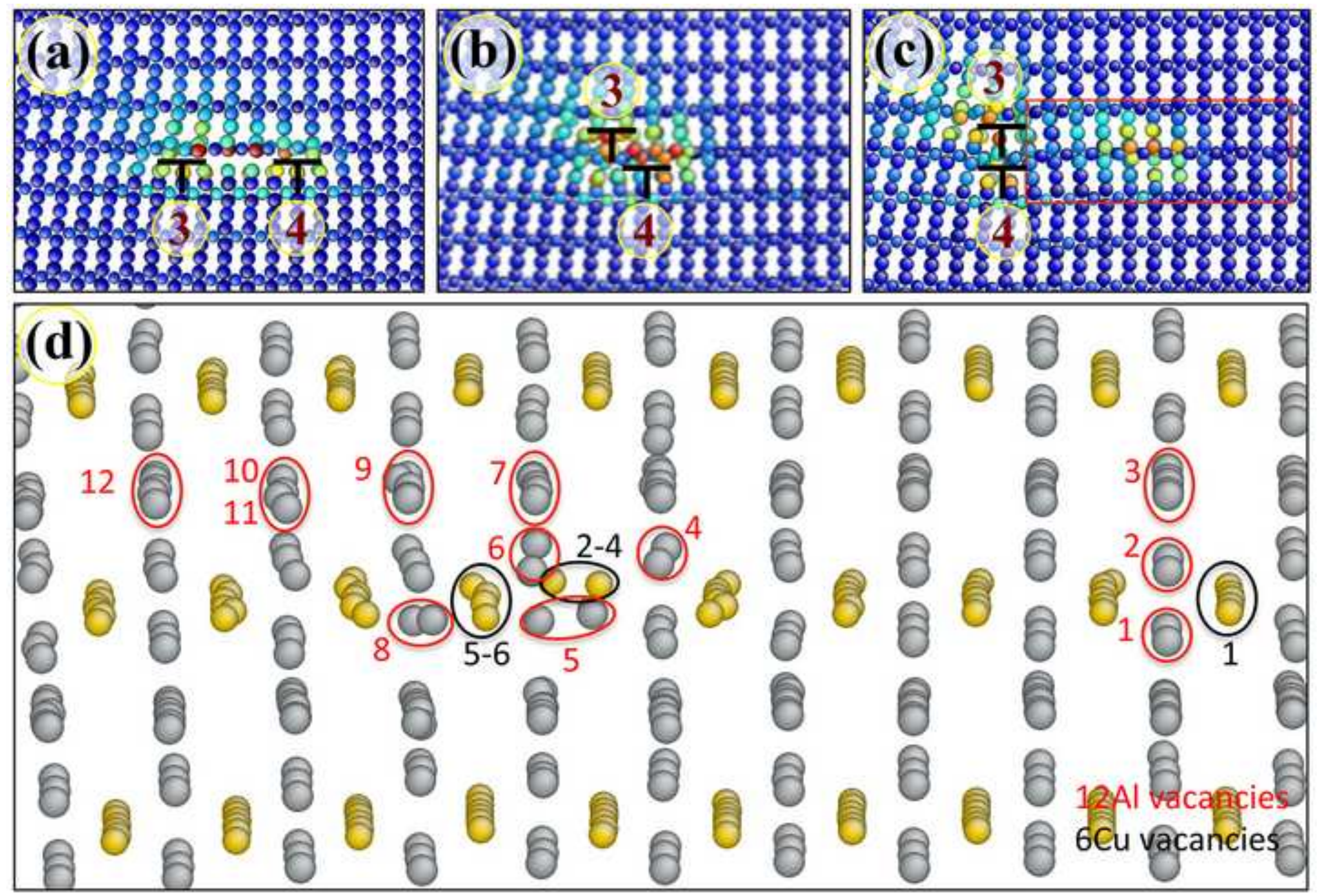

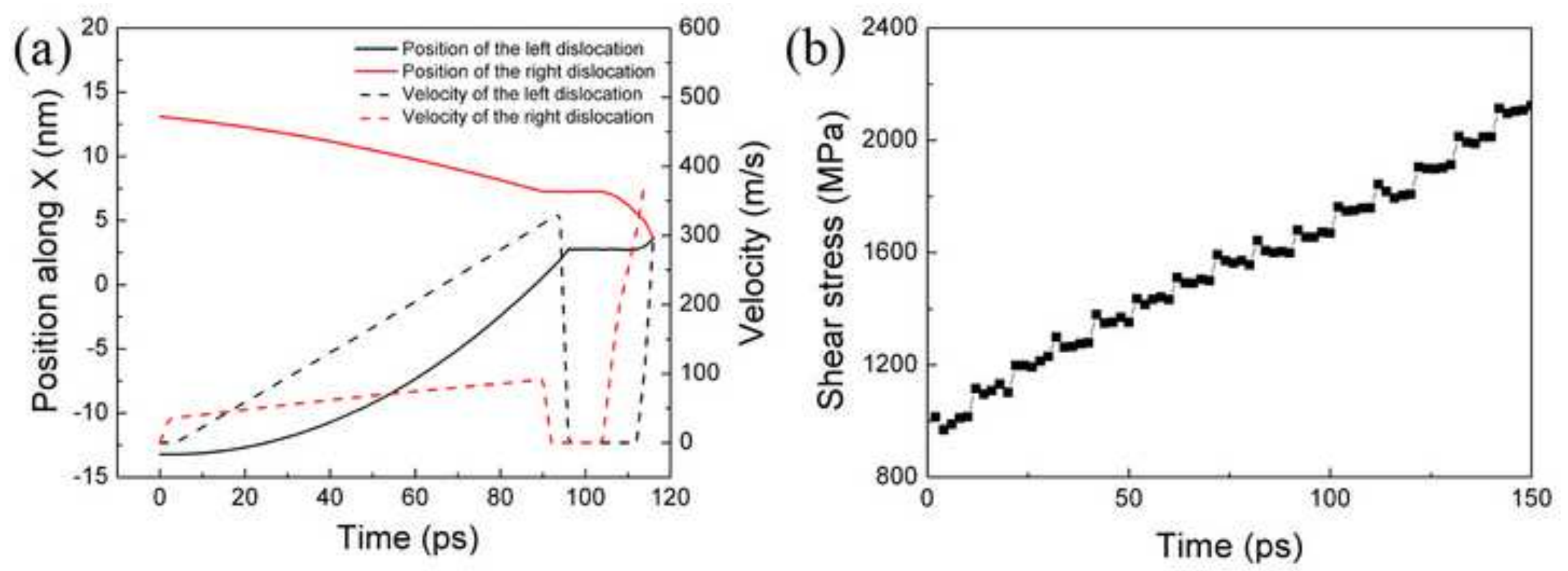
